\title{
Macro-Micro Response Characteristics of Surrounding Rock and Overlying Strata towards the Transition from Open-Pit to Underground Mining
}

\author{
Xiaoshuang Li, ${ }^{1,2,3,4}$ Shun Yang $\mathbb{D}^{1}{ }^{1}$ Yunmin Wang, ${ }^{3,4}$ Wen Nie, ${ }^{1}$ and Zhifang Liu ${ }^{1}$ \\ ${ }^{1}$ School of Resources and Environmental Engineering, Jiangxi University of Science and Technology, Ganzhou, Jiangxi 341000, China \\ ${ }^{2}$ School of Civil Engineering, Shaoxing University, Shaoxing Zhejiang 312000, China \\ ${ }^{3}$ State Key Laboratory of Safety and Health in Metal Mines, Maanshan, Anhui 243003, China \\ ${ }^{4}$ Sinosteel Maanshan General Institute of Mining Research Co. Ltd., Maanshan, Anhui 243000, China
}

Correspondence should be addressed to Shun Yang; 18720720706@163.com

Received 13 January 2021; Revised 25 February 2021; Accepted 1 April 2021; Published 7 May 2021

Academic Editor: Rihong Cao

Copyright (C) 2021 Xiaoshuang Li et al. This is an open access article distributed under the Creative Commons Attribution License, which permits unrestricted use, distribution, and reproduction in any medium, provided the original work is properly cited.

\begin{abstract}
The macro-micro mining response of the surrounding rock and overlying strata towards the transformation from open-pit to underground mining is examined in the present study, based on the engineering background of the Jinning phosphate mine (Yunnan Phosphate Chemical Group Co., Ltd.) via simulations involving similar materials, digital photographic measurement technology, and numerical simulation. The mining deformation of the surrounding rock underground, and of the overlying strata, is shown to develop in three stages, namely: (1) small and local deformation, (2) continuous linear increase, and (3) the violent nonlinear collapse of the entire system. The internal distribution of stress in the surrounding rock and adjacent overlying strata of the inclined mined-out area is complicated. The degrees of pressure increase and pressure relief have an important relationship with the size of the mining space. The pressure relief is more complete close to the mined area, and the stress reduction decreases with increasing distance. The cracks propagate in arc shapes and have a tendency to penetrate into the upper and lower ends of the stope. The size of the excavation space plays a key role in the generation, propagation, and penetration of the cracks. Due to the disturbance of the first mining level and the increase in excavation depth, the rate of damage to the surrounding and overlying rock increases in the second mining level. This process generates more cracks, which accelerate the instability of the surrounding rock and overlying strata.
\end{abstract}

\section{Introduction}

Most of China's open-pit mines were built in the 1950s. After several decades of continuous high-intensity mining, the vast majority of open-pit mines have entered the deep open-pit mining stage and even underground mining. The transition from open-pit to underground mining is a complex systems engineering problem, and the resulting deformation mechanism of the rock mass is highly complicated due to the effects of numerous stress fields. The process presents typical sudden and nonlinear characteristics and poses a serious challenge to the open-pit to underground mining project [1-5].
Research on the transition from open-pit to underground mining in China began around the 1990s, with many researchers conducting bottom friction modeling experiments $[6,7]$, physical modeling tests [8-10], numerical simulations [11-14], combined numerical and physical simulations [15-18], and field measurements [19-22]. Recently, a mathematical model was established to describe the attenuation of peak particle velocity (PPV) in the open-pit slope, which is used to evaluate the influence of underground mine blasting on the slope stability [23]. Cheng et al. used the Universal Distinct Element Code (UDEC) numerical method to simulate the movement of strata in the footwall caused by underground mining [24]. In addition, the discontinuous 
deformation analysis (DDA) method has been used to study the process of slope instability induced by the caving method in rock structures of various mass during mining from openpit to underground [25-27]. Regassa et al. used the equivalent discontinuity modeling method (EDMM) to simulate the rock movement and failure caused by mining under the end slope of the Western open pit of the Yanqianshan iron mine [28]. With advances in technology, researchers have used micro seismic monitoring, in situ monitoring, and true triaxial modeling [29-32] to investigate the deformation characteristics and failure mechanisms of the slope rock mass and the surrounding rock of the underground stope after the transition from open-pit to underground mining.

Nevertheless, few studies have examined the changes in the surrounding rock and overlying strata of the underground stope due to influences in slope and mining coupled. Due to major differences in the conditions, mining techniques, mining methods, and complexity of the open-pit slope and underground mining environments, it is necessary to study the macro-micro response characteristics of the surrounding rock and overlying strata to the transition from open-pit to underground mining. Therefore, taking the open-pit to underground mining project of the Jinning phosphate mine belonging to the Yunlin Group as an example, experiments on similar materials, numerical simulations, and theoretical analyses are used in the present study to investigate the mining response characteristics of the surrounding rock and overlying strata during such a transition.

\section{Engineering Background}

After more than 30 years of mining, part of the no. 2 pit in the Jinning phosphate mine belonging to the Yunnan Phosphate Chemical Group Co., Ltd. has formed a high and steep slope. Figure 1(a) is the second pithead of the Jinning phosphate mine. The mining area is low in the north and high in the south and inclined to the east and west. The highest point is $2320 \mathrm{~m}$, and the general elevation is between +2200 and $+2320 \mathrm{~m}$. The average dip angle of the ore body is $36^{\circ}$. The thickness of the ore body is generally $3-15 \mathrm{~m}$, with an average thickness of $6.8 \mathrm{~m}$, and the firmness coefficient of the deposit is 7-9. The roof is composed of dolomite with argillaceous rock (firmness coefficient: 6-10), and the floor is composed of argillaceous dolomite with a thin layer of chert (firmness coefficient: 14-16). There are few weak interlayers in the rock layer of the open-pit slope; thus, the influence of faults and joints is small. At present, the total mining depth of pit 2 is over $120 \mathrm{~m}$. The top slope angle is $45^{\circ}$, and the bottom slope angle is equal to the dip angle. Since only a small amount of geological reserves (above $+2270 \mathrm{~m}$ ) are available for openpit mining, the levels below this will be transferred to the underground mining stage. The representative section of exploration line 59 has been selected as the test section for the present study, and Figure 1(b) is the engineering geological section of exploration line 59. According to the actual mining process, one mining level per $50 \mathrm{~m}$ is selected for the study. The underground ore body is mined at a level of $10 \mathrm{~m}$ in each mining level.

\section{Macro Mining Response Characteristics: Similar Material Experiments}

3.1. Simulated Excavation. Experiment is the most traditional method in the field of geotechnical engineering [33-48]. In order to simulate the excavation from the open pit to underground, the two middle sections were selected; Figure 2 shows the two middle sections. In the actual mine, mining extended only to the $+2120 \mathrm{~m}$ level, and the maximum surface elevation was $+2320 \mathrm{~m}$ (see Figure 1(b)). In the present study, the simulated maximum mining depth and width are 200 and $300 \mathrm{~m}$, respectively. The overlying strata in the monitoring scheme area is uniformly divided into sixteen displacement observation lines at horizontal intervals of $0.1 \mathrm{~m}$, with the initial observation line positioned at $+2270 \mathrm{~m}$ at a horizontal distance of $0.116 \mathrm{~m}$ from the slope. In the vertical direction, the lowest observation point in each line is $0.1 \mathrm{~m}$ from the ore body, and the height of successive observation points increased in steps of $0.1 \mathrm{~m}$. In total, 128 deformation observation points are arranged in this experiment, Figure 2 is the simulation monitoring scheme.

Mining is performed via the sublevel caving method, Figure 3 shows the mining method and steps. The ore blocks are arranged along the strike and divided into two middle sections, each with a height of $0.5 \mathrm{~m}$. Both of the two middle sections are mined in 5 steps from bottom to top, with subsection heights of $0.1 \mathrm{~m}$. And the mining process is completed in 10 steps.

3.2. Model Design. The ore body is chiefly phosphate rock, with a footwall consisting primarily of boundary phosphate rock, mud-bearing dolomite, and layered dolomite. The upper section consists mainly of mudstone-bearing quartz sandstone, dolomite, and a quaternary clay layer. Table 1 shows the rock mechanical parameters measured by laboratory physical tests after field sampling, which reflects the mechanical properties of rock, and the similar physical model experiment material ratio is also based on the mechanical parameters.

Based on the principle of similar material simulation, the similarity parameters for each simulation test are as follows: geometry similarity ratio $=1: 100$, bulk density similarity ratio $=0.81: 1$, stress similarity ratio $=1: 123.50$, and time similarity ratio $=1: 10$. A plane stress model was used in the present work to simulate similar materials along the dip of the phosphate rock. The main components of the model materials were sand, gypsum, calcium carbonate, mica powder, soft glue, engine oil, fine wood chips, and water. The appropriate material ratios were selected via the orthogonal test method and the use of a material testing machine, and the dimensions of the plane model were $3.00 \times 0.30 \times 2.00$ $\mathrm{m}$ (length $\times$ width $\times$ height).

3.3. Physical Modeling Result Analysis. The vertical displacement of the surrounding rock and overlying strata at various stages of the model excavation was measured using a digital camera system. Figures 4(a)-4(f) are the subsidence displacements after the first, third, fifth, sixth, eighth, and tenth excavation steps of the similar material model, respectively. Here, 


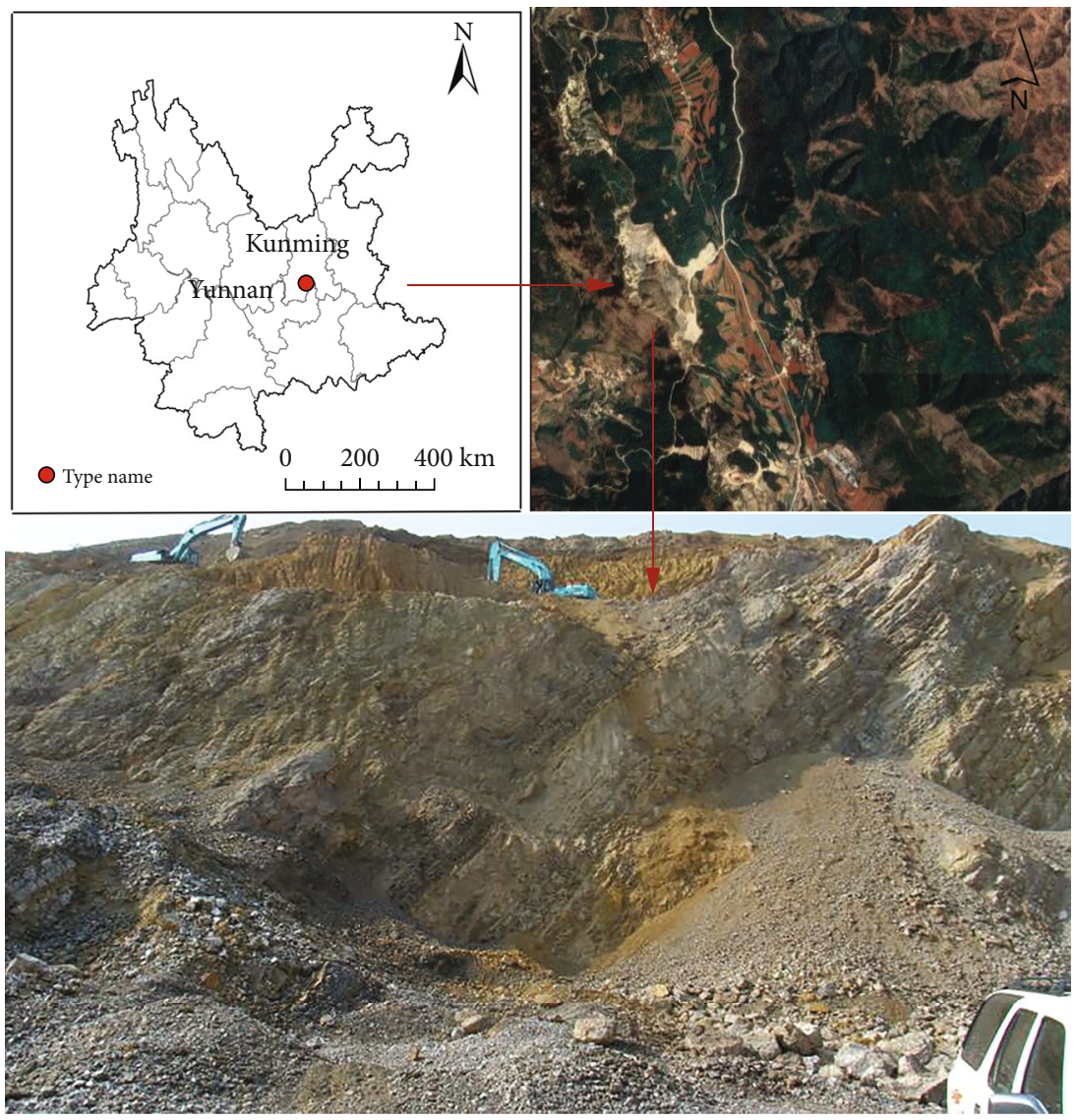

(a) Second pithead of the Jinning phosphate mine

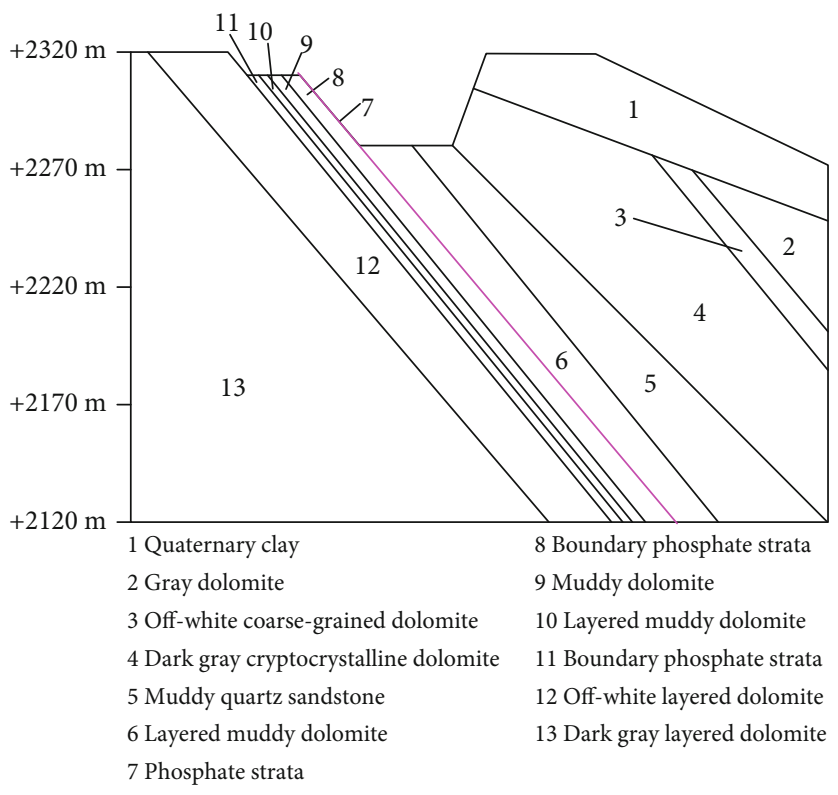

(b) Engineering geological section of exploration line 59

FIGURE 1: Engineering background.

the distance from the beginning of the ore body and the extent of subsidence are plotted as negative values.

These experimental results indicate that the deformation of the surrounding rock underground and the overlying strata during mining occurs in the following three stages: (i) small and local deformations occur during the initial excavation steps (steps 1-3, see Figures 4(a) and 4(b)), (ii) a continuous linear increase in deformation occurs during the intermediate excavation stages (steps 4-8, see Figures 4(c)$4(\mathrm{e})$ ), and (iii) a violent nonlinear collapse of the entire 


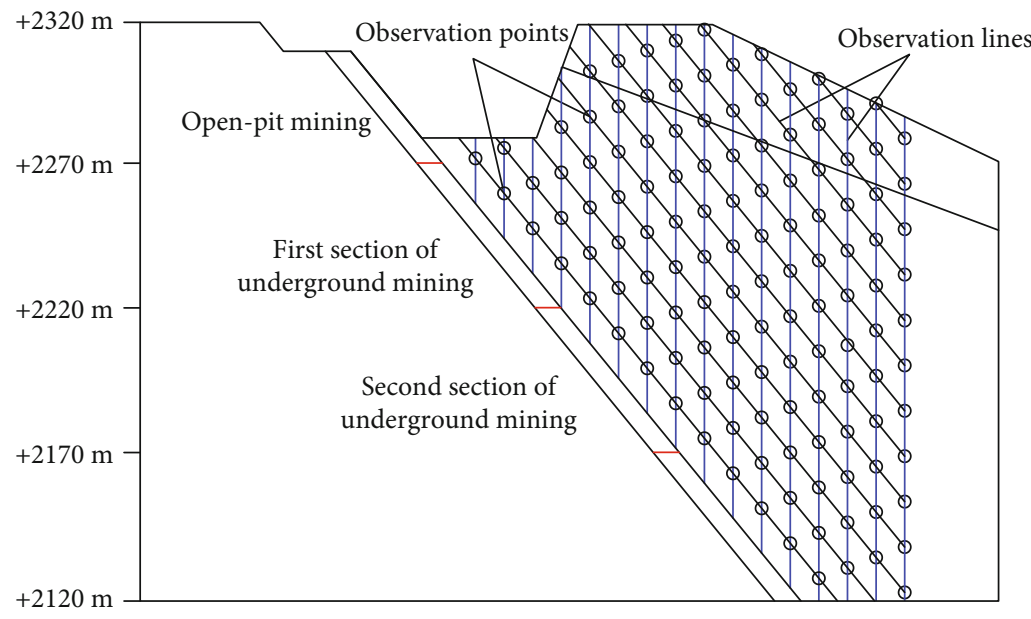

Figure 2: Simulation monitoring scheme.

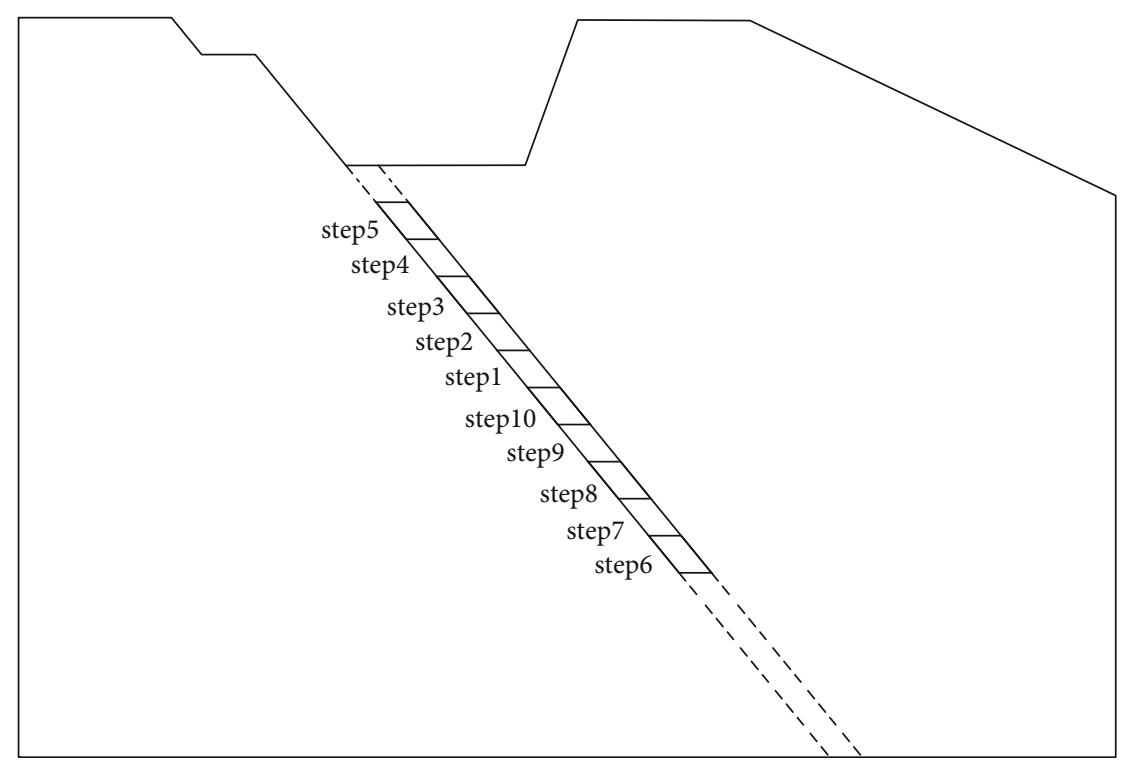

Figure 3: Mining method and steps.

structure occurs during the final excavation stages (steps 910, see Figure 4(f)).

In detail, an examination of Figure 4(a) indicates that only 10 observation points on lines 1-3 in the vicinity of the mined-out area are deformed, with a maximum subsidence of $5 \mathrm{~mm}$ in the central area of the stope. After steps 1-3 (see Figure 4(b)), small degrees of separation and caving have occurred in the rock mass, while it still remains intact and stable. As the mining process is continued (see Figure 4(c)), the underground mining space increases. The effects extend to line 5 on the right-hand side of the underground stope, and the disturbance becomes more serious. At this time, the maximum subsidence increases to $20.5 \mathrm{~mm}$, and the deformation of the surrounding rock and overlying strata of the stope becomes intense in the area of stopes 2 and 3 . The maximum vertical displacement has increased to $25.5 \mathrm{~mm}$. After the eighth excavation step (see Figure 4(e)), the affected area extends to observation line 6 , and the severe deformation is mainly distributed along observation lines 1-2 on the upper left and lines 3-4 on the upper right. At this time, the maximum vertical subsidence has increased to $31.5 \mathrm{~mm}$. After the tenth excavation step (see Figure 4(f)), the mined area of the two middle sections is connected, the old mined area is "activated," and large numbers of macro through-cracks and large-scale pull-through microcracks are produced. At this time, the area affected by mining activity is seen to have increased sharply to $130 \mathrm{~cm}$, the maximum displacement has increased to $33.2 \mathrm{~mm}$, and the surface of the local area has collapsed.

In total, a gently inclined and thin- to medium-thick phosphate deposit was shown to transfer from the open pit to underground by the sublevel caving method, and the corresponding global subsidence curve (see Figure 4, the measure line $10 \mathrm{~m}$ and $20 \mathrm{~m}$ away from the stope) evolves from the irregular shape of a ladle to the final shape of a halfbowl. The results of the similar material model indicate that, 
TABLE 1: Rock mechanical properties.

\begin{tabular}{|c|c|c|c|c|c|}
\hline Lithology & $\begin{array}{l}\text { Bulk density } \\
(\gamma)\left(\mathrm{kN} \cdot \mathrm{m}^{-3}\right)\end{array}$ & $\begin{array}{c}\text { Modulus of elasticity } \\
(E)(\mathrm{GPa})\end{array}$ & $\begin{array}{c}\text { Compressive strength } \\
\left(\sigma_{\mathrm{c}}\right)(\mathrm{MPa})\end{array}$ & Poisson ratio $(\mu)$ & $\begin{array}{c}\text { Tensile strength } \\
\left(\sigma_{\mathrm{t}}\right)(\mathrm{MPa})\end{array}$ \\
\hline Quaternary clay & 18.00 & 3.28 & 5.12 & 0.46 & 0 \\
\hline Gray dolomite & 25.80 & 9.93 & 29.10 & 0.31 & 0.71 \\
\hline Off-white coarse-grained dolomite & 25.28 & 9.99 & 31.50 & 0.29 & 0.78 \\
\hline Dark gray cryptocrystalline dolomite & 25.80 & 9.93 & 29.10 & 0.31 & 0.89 \\
\hline Layered muddy dolomite & 26.20 & 9.14 & 24.78 & 0.28 & 0.92 \\
\hline Muddy dolomite & 24.79 & 6.06 & 17.10 & 0.34 & 0.67 \\
\hline Phosphatic bed & 19.50 & 8.10 & 22.87 & 0.39 & 0.88 \\
\hline Boundary phosphate rock & 26.60 & 13.80 & 37.96 & 0.30 & 1.46 \\
\hline Off-white layered dolomite & 26.24 & 14.60 & 48.13 & 0.28 & 1.66 \\
\hline Charcoal gray layered dolomite & 25.00 & 15.80 & 39.35 & 0.33 & 1.40 \\
\hline
\end{tabular}

near the mined-out area, the surrounding rock and overlying strata of a gently inclined, thin- to medium-thick phosphate deposit begin to deform and break after 1-10 excavation steps. During this process, the rock will bend and sink under the influence of the gravity and mining stress, to finally collapse when the internal stress exceeds the limiting strength of the rock stratum. The failure modes of sinking, bending, and breaking are identical for the upper and lower strata, and failure of the surrounding and overlying rock gradually progresses from the bottom to the top.

\section{Micro Mining Response Characteristics: Numerical Simulation}

4.1. Model Geometry and Boundary Conditions. In recent years, computer technology has developed rapidly, and numerical simulation has become an important research method [49-70]. Based on the specific geological conditions and mechanical parameters of the deep inclined mediumthick phosphate ore body in the northern area of pit 2 (Jinning County phosphate mine), a particle flow code (PFC) numerical model was run with the same size as that of the similar material model, i.e., height $\times$ width $=300 \mathrm{~cm} \times 200$ $\mathrm{cm}$; Figure 5(a) shows the particle flow code (PFC) model diagram, and Figure 5(b) shows the initial state of the model.

4.2. Physical and Mechanical Parameters of the Rock. The mesomechanical parameters of the PFC model were based on the measured mechanical properties of rock samples obtained on site. They account for the size effect and similarity ratio via repeated adjustments to make the simulated settlement close to that of the similar material model. Figure 6(a) shows the comparative picture of the experiment and simulation, Figure 6(b) shows the subsidence curve of the experiment and simulation, and Figure 6 shows the total comparative results of the similar material model and the PFC numerical model, the results illustrated the effectiveness of this simulation method, and this method can be used to analyze the mechanical behavior of surrounding rock and overlying strata during the mining process. Table 2 shows the final PFC mesoparameters of the rock samples, and the
PFC calculated results are consistent with the similar material model experiment.

4.3. Model Measuring Circle Layout. According to the mine pressure theory, after the underground mining, the surrounding rock and overlying strata are affected by mining stress and mined-out areas, and the in situ stress will redistribute. Figure 7 shows the in situ stress distribution after excavation step 1 , step 2 , step 5, and step 10, which illustrate the pressure increase and pressure relief zone of the surrounding rock and overlying strata near the goaf.

To analyze the stress changes in the surrounding rock and overlying strata at various locations after the first and second excavation steps, measuring circles were laid out in the surrounding rock, roof corner, and floor corner of the mined-out area, respectively. Figures $8(\mathrm{a})$ and $8(\mathrm{~b})$ show the layout of survey points on the surrounding rock and overlying strata in the PFC model for the first excavation step and the second excavation step, respectively. The left measuring circles (5 and 51) and the right measuring circles ( 2 and 21) were $0.03 \mathrm{~m}$ away from the rock surrounding the excavation. The measuring line was arranged at an angle bisecting the roof and floor corner, with each measuring circle positioned $0.03 \mathrm{~m}$ away from the mined area (circles $1,3,4$, and 6 and 11,31, 41, and 61). Another six measurement circles (1, 7 , and 8 and 11,71 , and 81 ) were set at vertical intervals of $0.09 \mathrm{~m}$ on the right-hand corner of the roof in order to analyze the changes in the internal stress of the overlying strata. All measuring circles had a radius of $0.03 \mathrm{~m}$.

\subsection{PFC Simulation Results and Analysis}

4.4.1. Stress Characteristics of the Surrounding Rock and Overlying Strata after Each Excavation Step. Figures 9(a) and 9(b) show the stress evolution in the overlying strata at the upper right-hand corner of the roof and the lower lefthand corner of the floor after the first excavation step (measurement circles 1 and 4, respectively) and after the second excavation step (measurement circles 11 and 41, respectively). The stress evolution curves at the end of each excavation step indicate that the surrounding rocks experience three stress evolution stages: (i) unloading, (ii) fluctuation, and (iii) 
Distance from the beginning of ore body $(\mathrm{cm})$

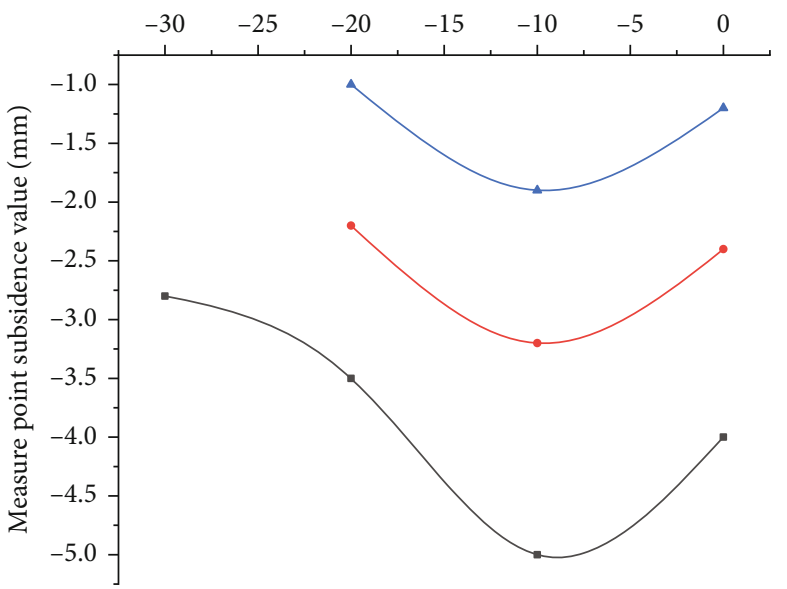

$\rightarrow$ Measure point $10 \mathrm{~m}$ away from the stope

$\longrightarrow$ Measure point $20 \mathrm{~m}$ away from the stope

^_ Measure point $30 \mathrm{~m}$ away from the stope

(a) First excavation step

Distance from the beginning of ore body $(\mathrm{cm})$

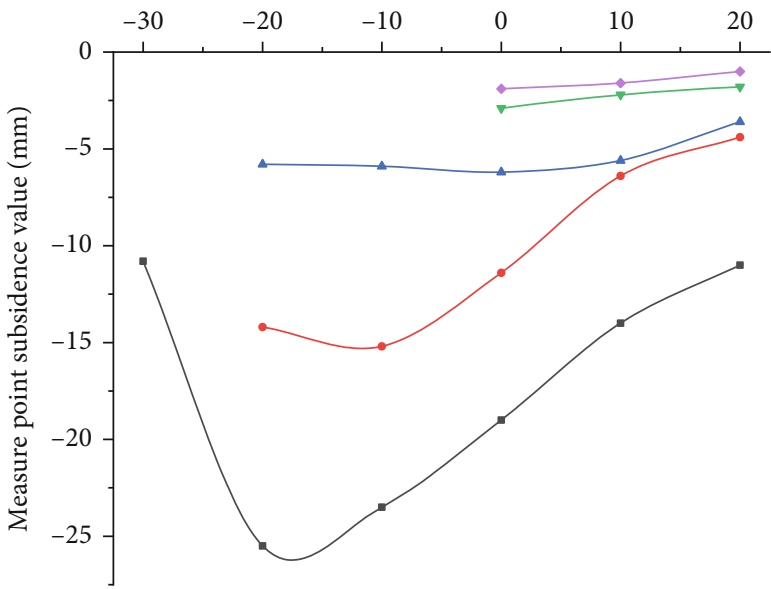

$\simeq$ Measure point $10 \mathrm{~m}$ away from the stope

- Measure point $20 \mathrm{~m}$ away from the stope

—- Measure point $30 \mathrm{~m}$ away from the stope

$\longrightarrow$ Measure point $40 \mathrm{~m}$ away from the stope

$\ldots$ Measure point $50 \mathrm{~m}$ away from the stope

(c) Fifth excavation step
Distance from the beginning of ore body $(\mathrm{cm})$

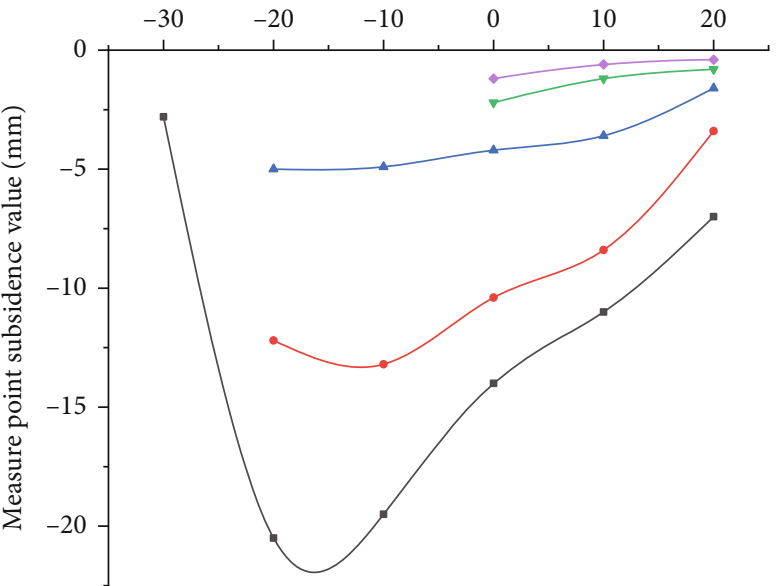

- Measure point $10 \mathrm{~m}$ away from the stope

- Measure point $20 \mathrm{~m}$ away from the stope

— Measure point $30 \mathrm{~m}$ away from the stope

—- Measure point $40 \mathrm{~m}$ away from the stope

- Measure point $50 \mathrm{~m}$ away from the stope

(b) Third excavation step

Distance from the beginning of ore body $(\mathrm{cm})$

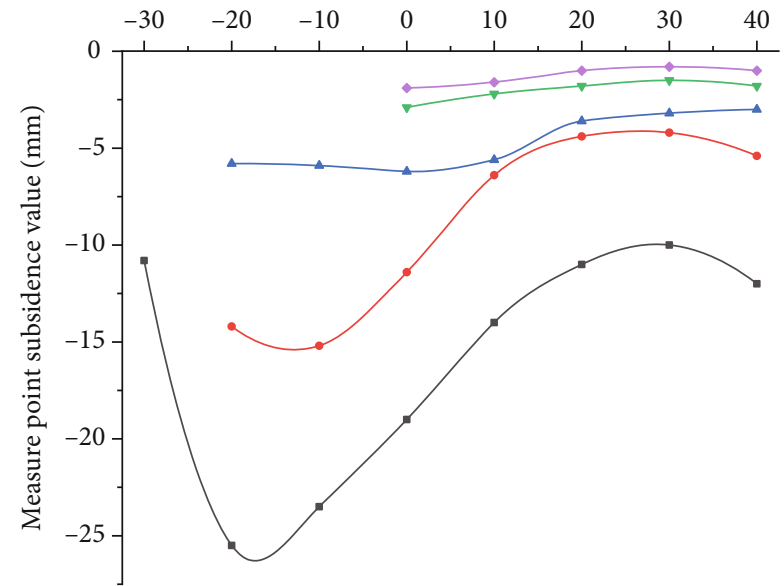

$\rightarrow$ Measure point $10 \mathrm{~m}$ away from the stope

- Measure point $20 \mathrm{~m}$ away from the stope

— Measure point $30 \mathrm{~m}$ away from the stope

- Measure point $40 \mathrm{~m}$ away from the stope

$\longrightarrow$ Measure point $50 \mathrm{~m}$ away from the stope

(d) Sixth excavation step

FIgURE 4: Continued. 
Distance from the beginning of ore body $(\mathrm{cm})$

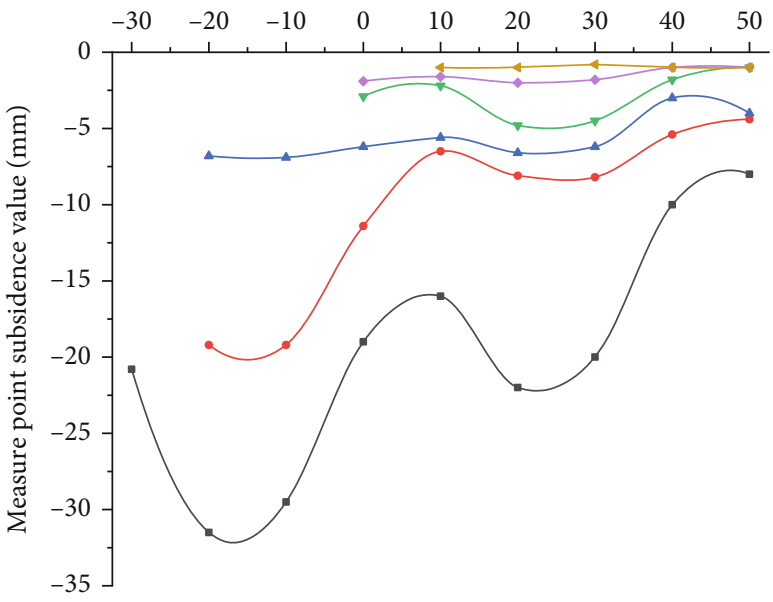

$\rightarrow-$ Measure point $10 \mathrm{~m}$ away from the stope

- Measure point $20 \mathrm{~m}$ away from the stope

—- Measure point $30 \mathrm{~m}$ away from the stope

$\longrightarrow$ Measure point $40 \mathrm{~m}$ away from the stope

—- Measure point $50 \mathrm{~m}$ away from the stope

— Measure point $60 \mathrm{~m}$ away from the stope

(e) Eighth excavation step
Distance from the beginning of ore body $(\mathrm{cm})$

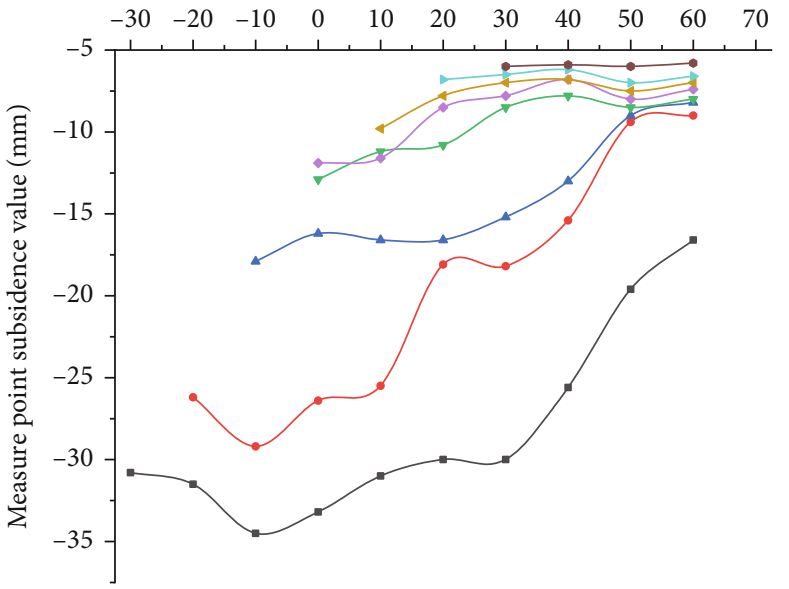

- Measure point $10 \mathrm{~m}$ away from the stope

- Measure point $20 \mathrm{~m}$ away from the stope

$\multimap$ Measure point $30 \mathrm{~m}$ away from the stope

- Measure point $40 \mathrm{~m}$ away from the stope

$\longrightarrow$ Measure point $50 \mathrm{~m}$ away from the stope

— Measure point $60 \mathrm{~m}$ away from the stope

$\rightarrow$ Measure point $70 \mathrm{~m}$ away from the stope

$\rightarrow$ Measure point $80 \mathrm{~m}$ away from the stope

(f) Tenth excavation step

Figure 4: Subsidence displacements after each excavation step of the similar material model.

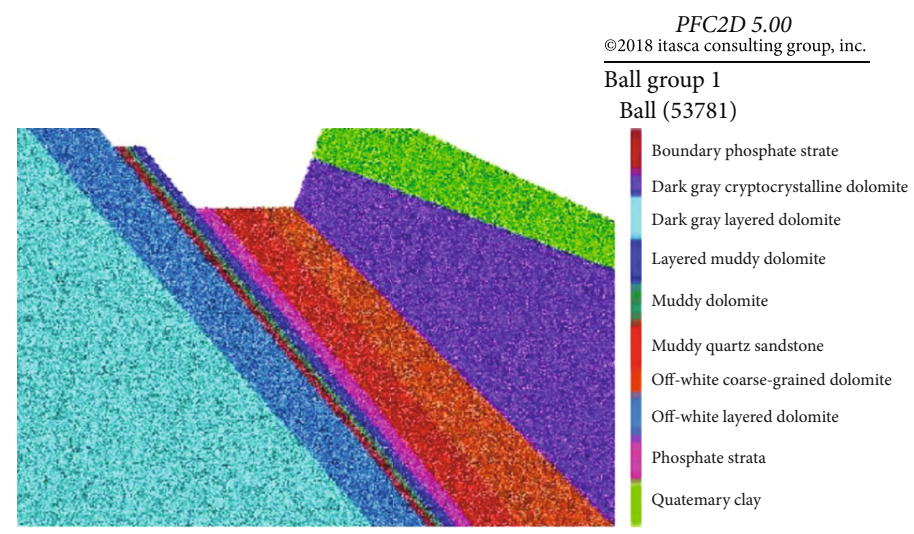

(a) Particle flow code (PFC) model diagram

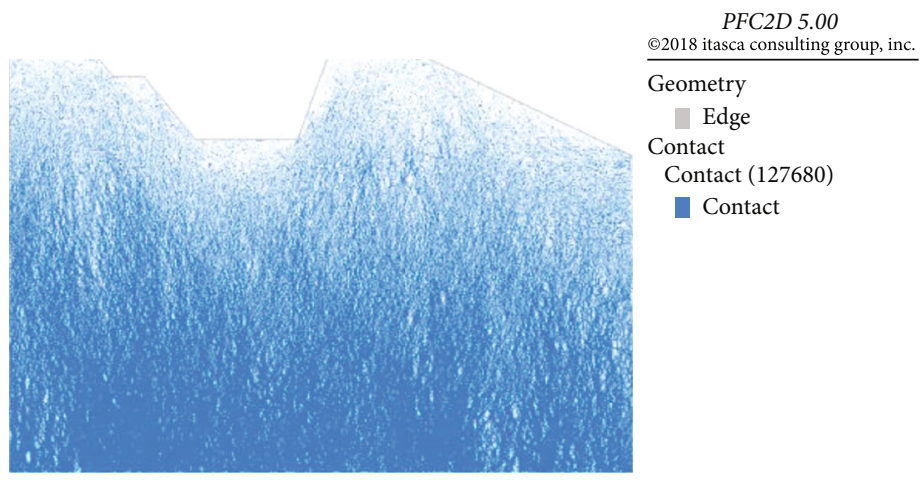

(b) Initial contact force distribution

Figure 5: Particle flow code (PFC) model diagram and initial contact force distribution. 


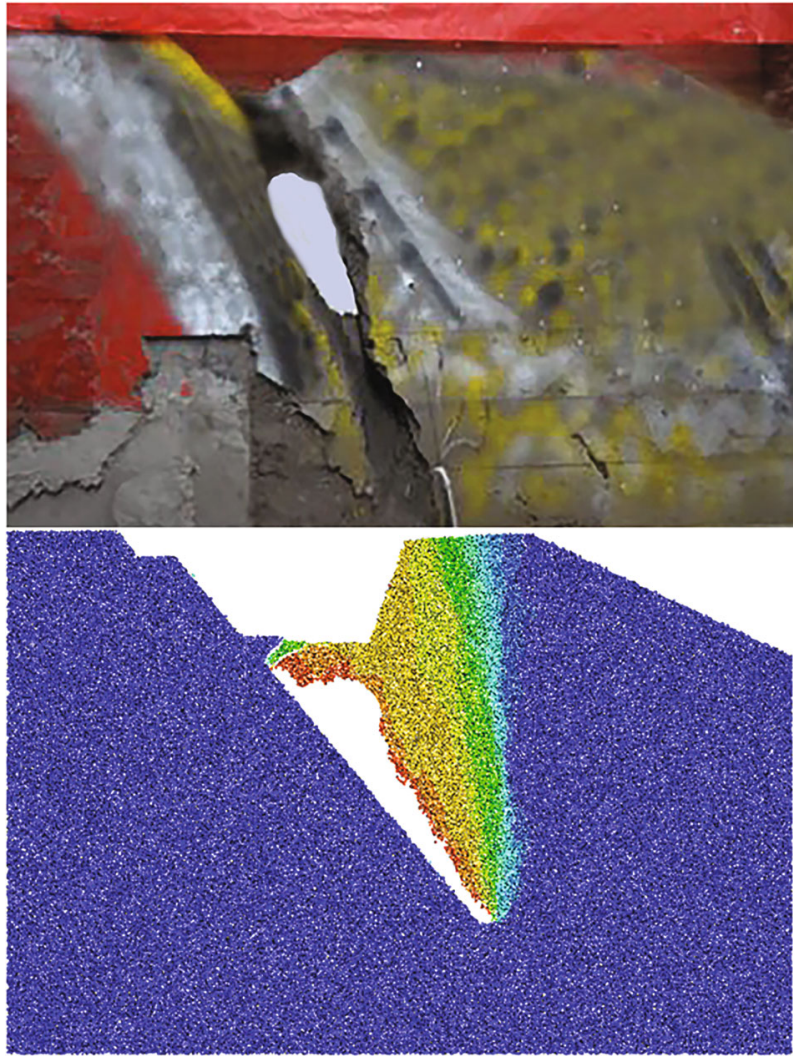

(a) Comparative picture

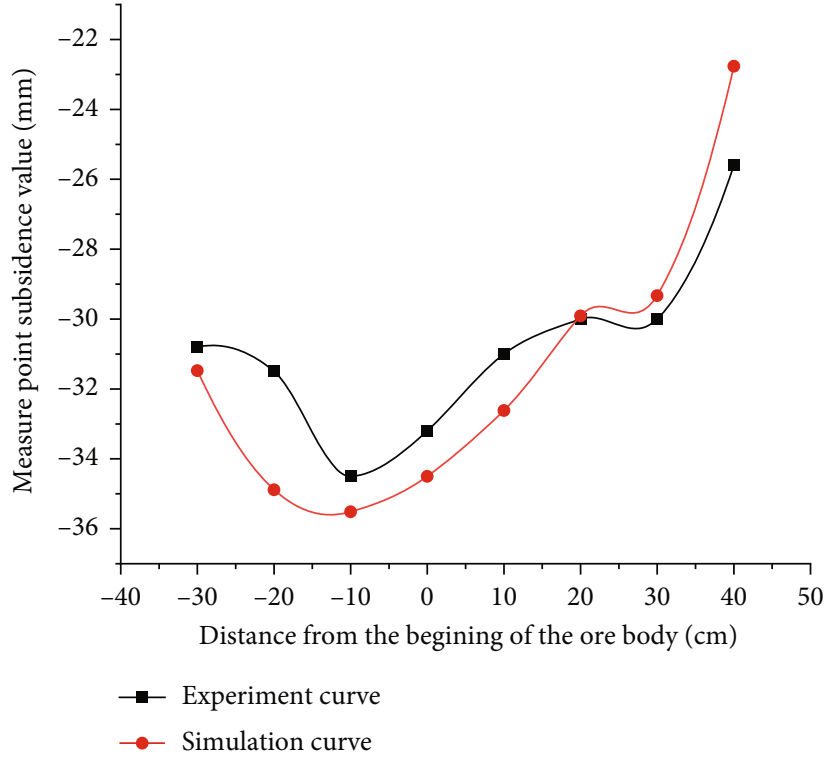

(b) Comparative curve

FIgURE 6: Comparative results of the similar material model and the PFC numerical model.

TABLE 2: The final PFC mesoparameters of the rock samples.

\begin{tabular}{|c|c|c|c|c|c|c|}
\hline Rock type & $\begin{array}{l}\text { Parallel bond modulus } \\
(\mathrm{gPa})\end{array}$ & $\begin{array}{c}\text { Cohesion } \\
(\mathrm{kPa})\end{array}$ & $\begin{array}{c}\text { Tension } \\
(\mathrm{kPa})\end{array}$ & $\begin{array}{c}\text { Friction } \\
\left({ }^{\circ}\right)\end{array}$ & $\begin{array}{l}\text { Stiffness } \\
\text { ratio }\end{array}$ & $\begin{array}{c}\text { Density } \\
\left(\mathrm{kg} / \mathrm{cm}^{3}\right)\end{array}$ \\
\hline Quaternary clay & 0.17 & 7.37 & 7.37 & 18.2 & 2.1 & 1458 \\
\hline $\begin{array}{l}\text { Dark gray cryptocrystalline } \\
\text { dolomite }\end{array}$ & 0.19 & 8.42 & 8.42 & 30.20 & 2.1 & 2089 \\
\hline Off-white coarse-grained dolomite & 0.21 & 7.04 & 7.04 & 29.66 & 2.1 & 2090 \\
\hline Muddy quartz sandstone & 0.16 & 7.04 & 7.04 & 29.52 & 2.1 & 2122 \\
\hline Phosphate strata & 0.23 & 10.14 & 10.14 & 30.53 & 2.1 & 2155 \\
\hline Layered muddy dolomite & 0.24 & 13.44 & 13.44 & 30.17 & 2.1 & 2122 \\
\hline Muddy dolomite & 0.25 & 11.32 & 11.32 & 33.23 & 2.1 & 2065 \\
\hline Boundary phosphate strata & 0.26 & 11.81 & 11.81 & 30.89 & 2.1 & 2078 \\
\hline Off-white layered dolomite & 0.29 & 21.86 & 21.86 & 47.23 & 2.1 & 2025 \\
\hline Dark gray layered dolomite & 0.26 & 22.67 & 22.67 & 30.17 & 2.1 & 2125 \\
\hline
\end{tabular}

Note: the minimum particle radius is $4 e-3 \mathrm{~m}$, and the particle size ratio is 1.5 .

stabilization. The larger the mining space, the longer the fluctuation time. In detail, the curves in Figure 9(a) reveal that the internal stress in the surrounding rocks at the upper right-hand corner of the roof (measurement circle 1 , Figure 8(a)) and the lower left-hand corner of the floor (measurement circle 4, Figure 8(a)) decreases after the first excavation step, thus indicating a process of unloading. After the second excavation step (Figure $8(\mathrm{~b})$ ), the internal stress in the surrounding rock at the upper right-hand corner of the roof (measurement circle 11, Figure 8(b)) and the bottom left-hand corner (measurement circle 41, Figure 8(b)) continues to decrease, but the situation is no longer identical at the two locations. Thus, the amplitude of unloading of measurement circle 11 is $8 \mathrm{kPa}$, while the circle 41 is about $3 \mathrm{kPa}$. The final absolute stress value of measurement circle 11 after the second excavation step is about $0 \mathrm{kPa}$. This indicates that 


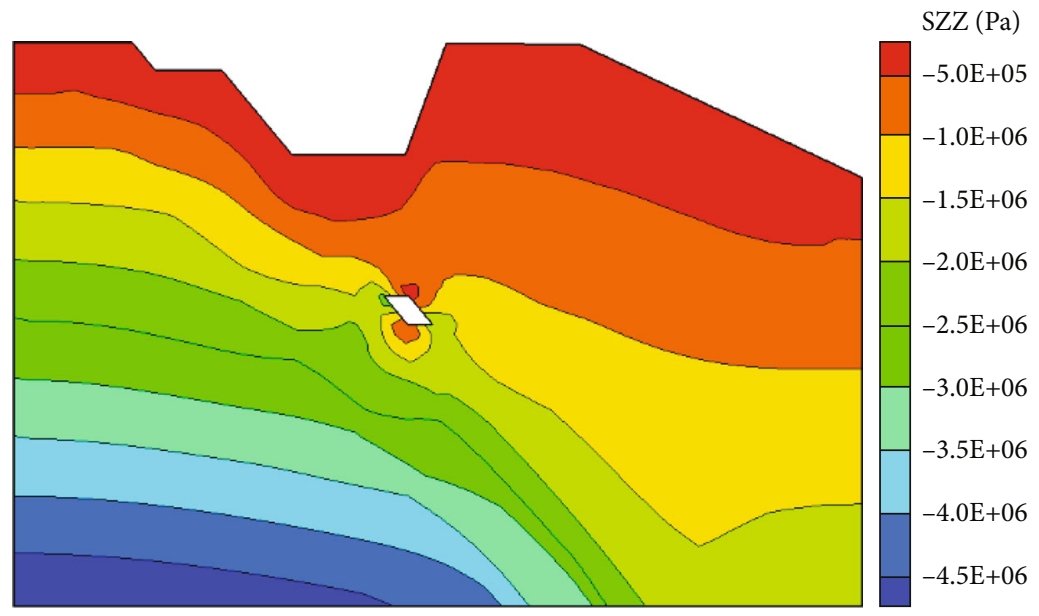

(a) First excavation step

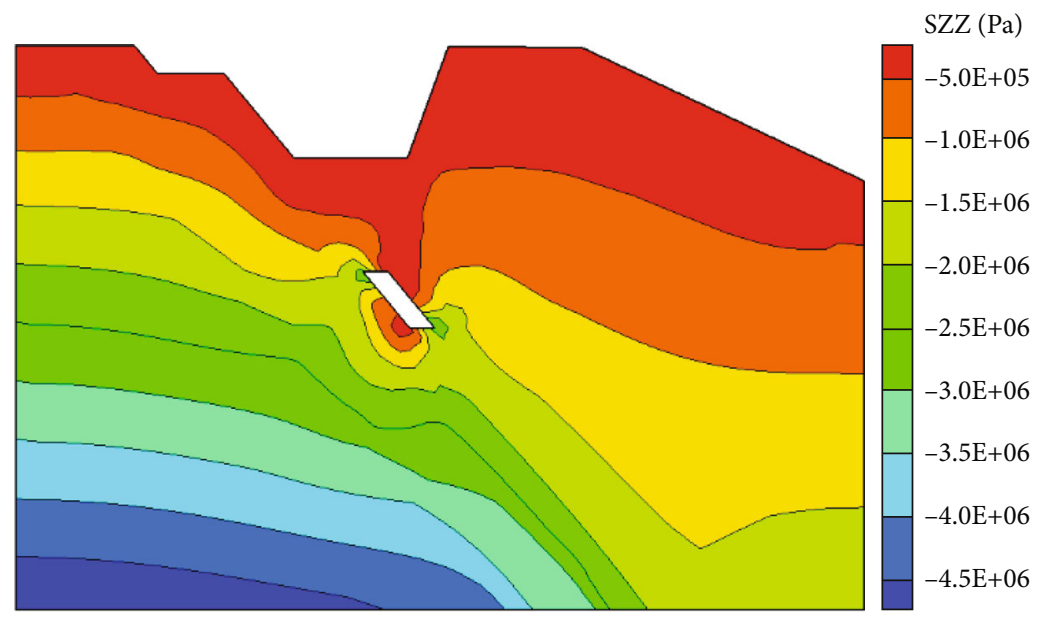

(b) Second excavation step

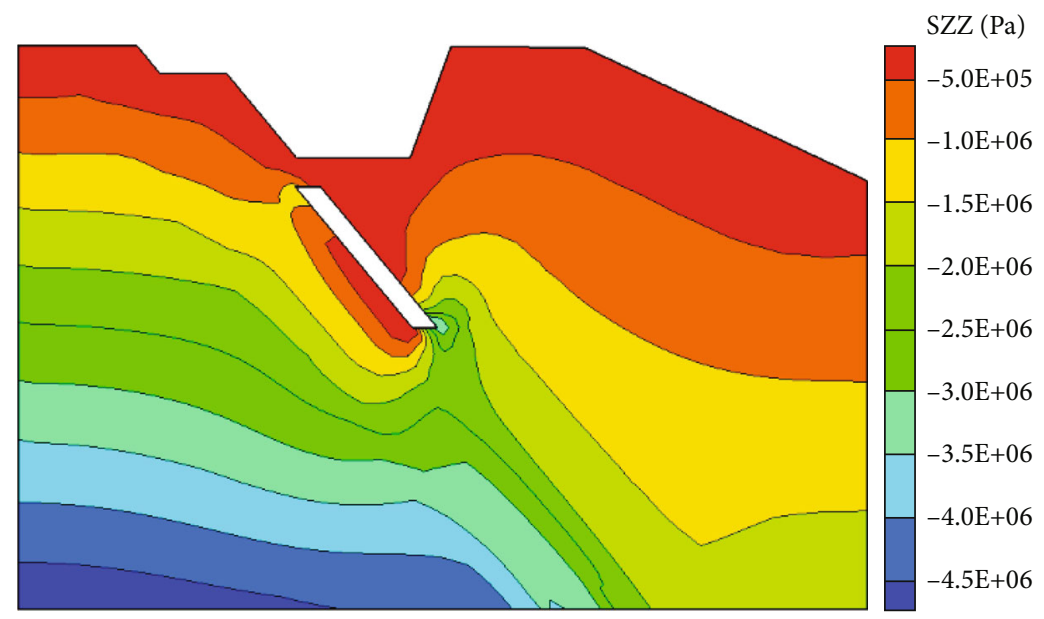

(c) Fifth excavation step

Figure 7: Continued. 


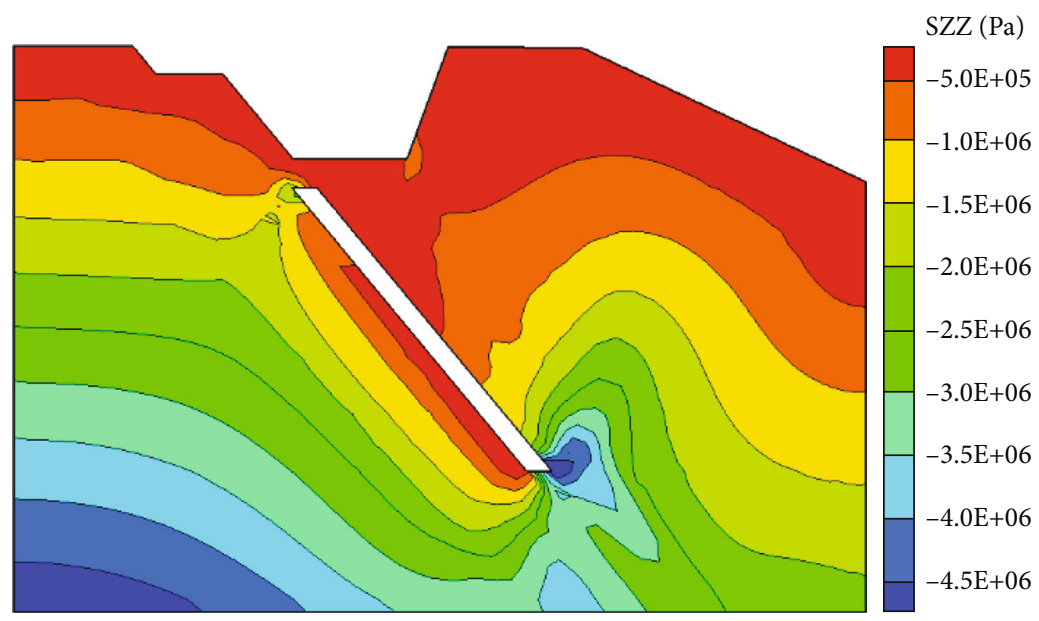

(d) Tenth excavation step

FIgURE 7: Stress distribution after underground excavation.

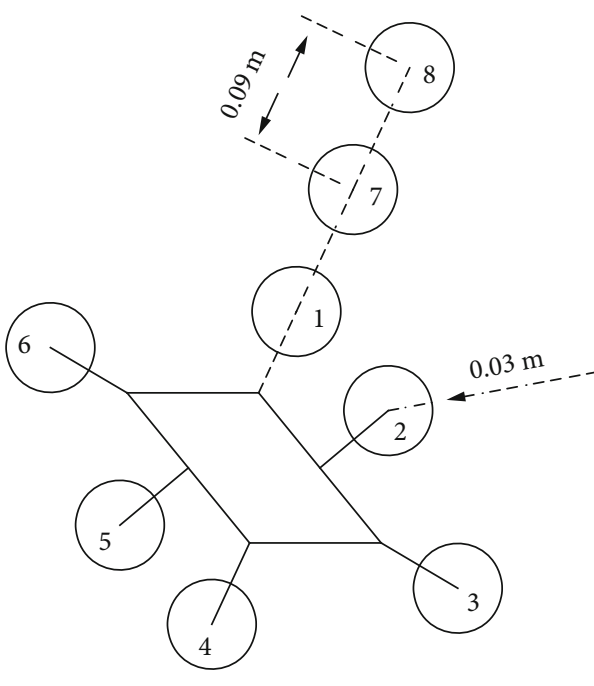

(a) The layout of survey points for the first step

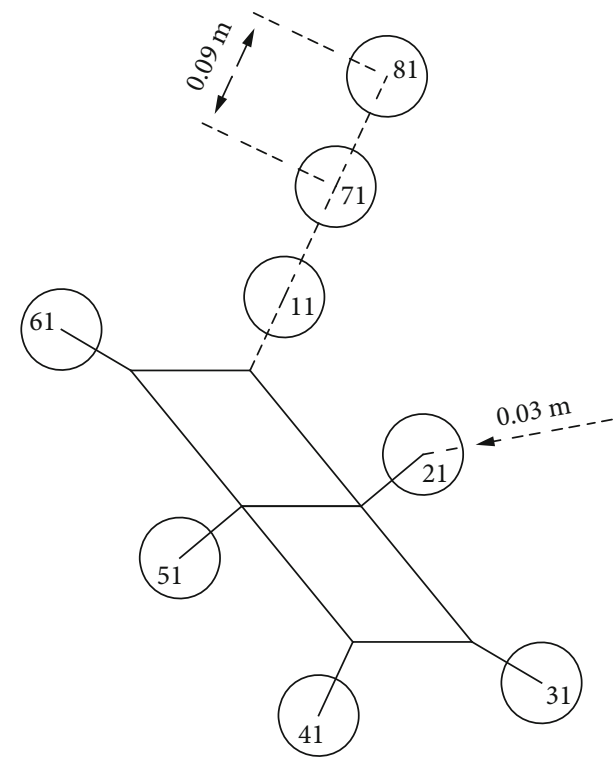

(b) The layout of survey points for the second step

FIgURE 8: The layout of survey points on the surrounding rock and overlying strata in the PFC model for the first excavation step and the second excavation step.

the surrounding rocks at this location are now in a state of stress balance. However, as the excavation space increases during subsequent excavation steps, the unloading area will continue to increase. Hence, due to gravity, this part of the surrounding rock could be placed under tension accompanied by internal bonds breaking and cracks appearing.

Figures 10(a) and 10(b) show the stress evolution in the overlying strata on the right-hand side of the roof and the left-hand side of the floor after the first excavation step (measurement circles 2 and 5, respectively) and after the second excavation step (measurement circles 21 and 51, respectively). An examination of Figure 10(a) indicates that the internal stress of the surrounding rocks on the left and right sides is increased at the end of the first excavation step. In addition, the increase in stress on the left side of the floor (measurement circle 5, Figure 8(a)) is more pronounced with a maximum amplitude of $\sim 3 \mathrm{kPa}$, whereas that on the right (measurement circle 2, Figure 8(a)) increases slightly. As the mining space is increased during the second excavation step (Figure 10(b)), the pressure on measurement circle 21 continues to increase, whereas that on measurement circle 51 is significantly decreased, because the surrounding rock on the left side of the floor is continuously unloaded during the second excavation step. The absolute stress on the surrounding rocks on the right and left sides at the end of the second excavation step is about $8 \mathrm{kPa}$ and $10 \mathrm{kPa}$, respectively, thus indicating that the rock mass was not damaged or moved. The above analysis indicates that the internal stress in the surrounding rocks on the left and right sides changes in a complicated manner as the excavation space is 


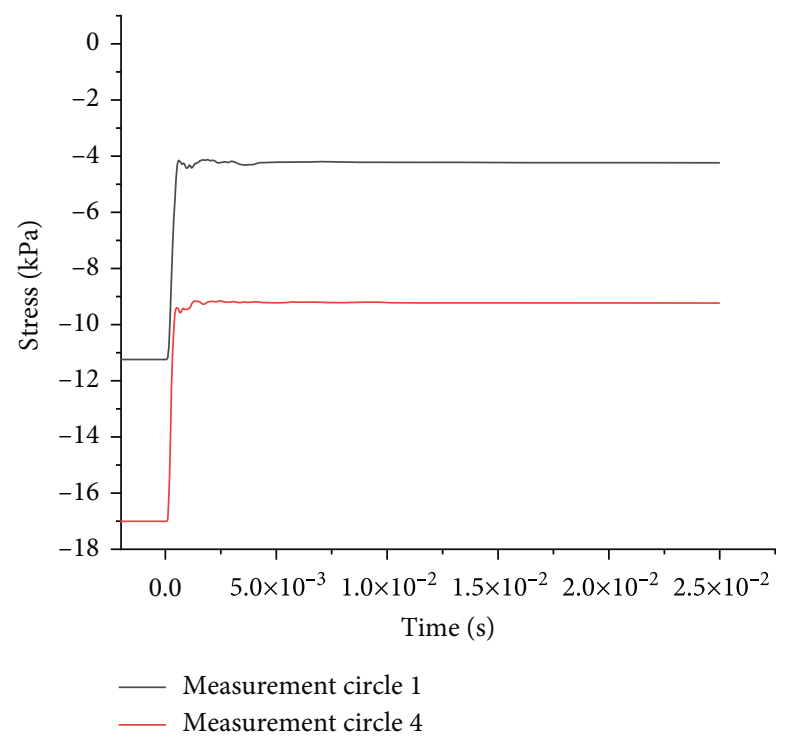

(a) First excavation step

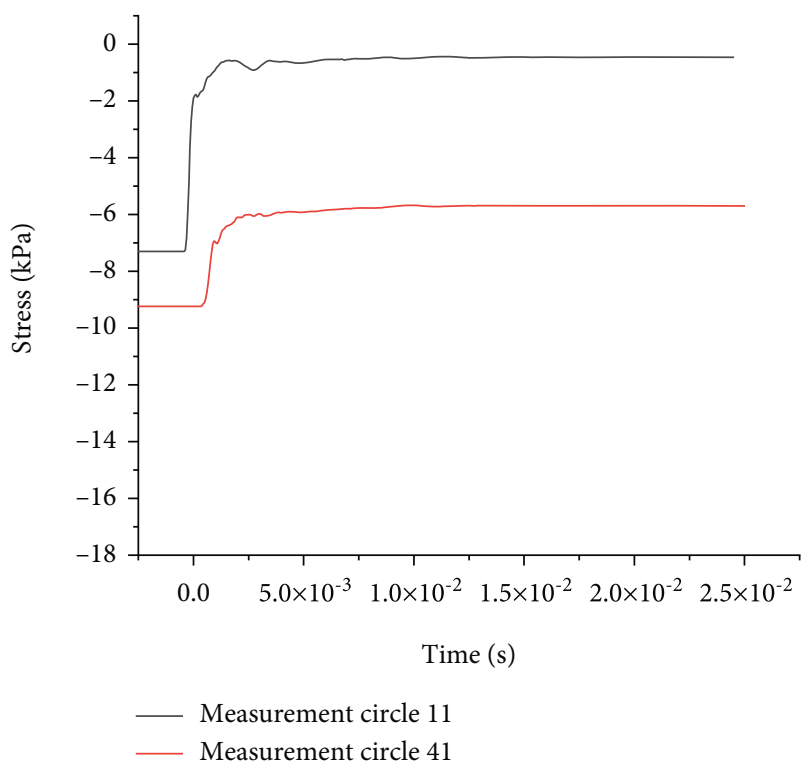

(b) Second excavation step

FiguRE 9: Stress evolution in the overlying strata at the upper right-hand corner of the roof and the lower left-hand corner of the floor after the first excavation step (measurement circles 1 and 4, respectively) and after the second excavation step (measurement circles 11 and 41 , respectively).

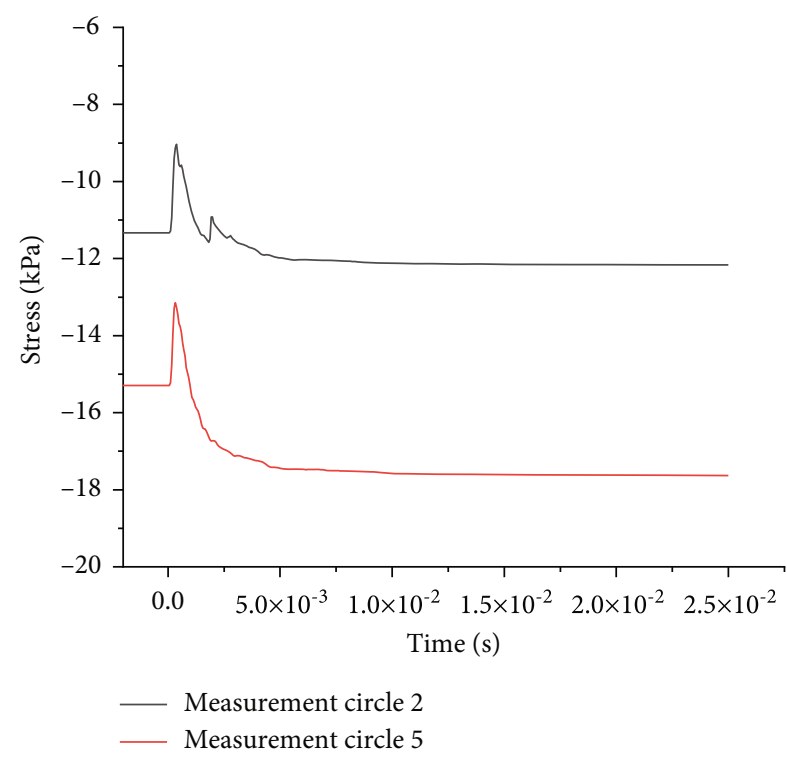

(a) First excavation step

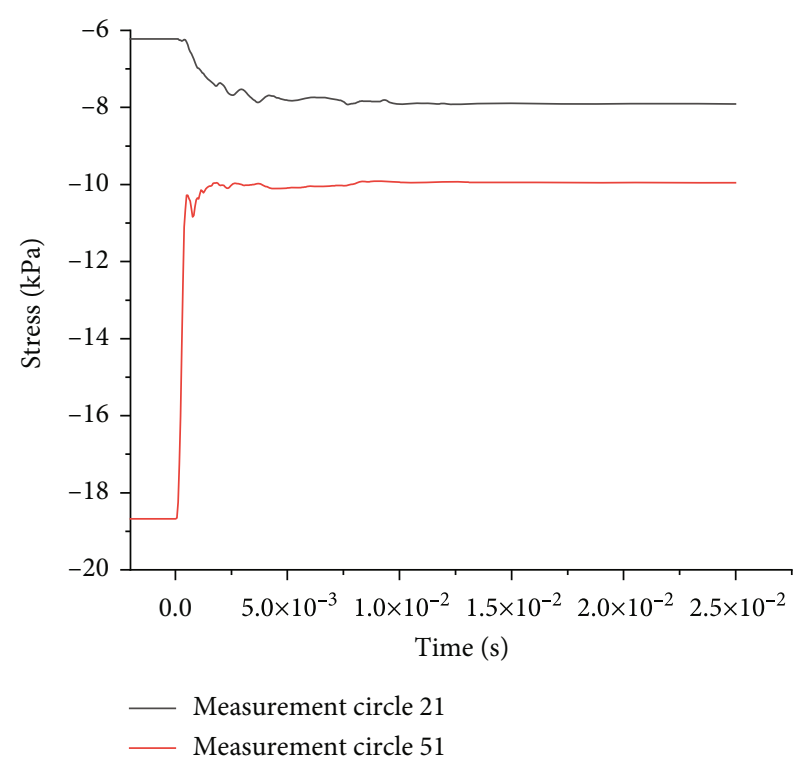

(b) Second excavation step

FIGURE 10: Stress evolution in the overlying strata on the right-hand side of the roof and the left-hand side of the floor after the first excavation step (measurement circles 2 and 5, respectively) and after the second excavation step (measurement circles 21 and 51, respectively).

increased. Hence, the scope of the mining space is a key factor affecting the increase in internal stress or the relief of the surrounding rocks.

Figures 11(a) and 11(b) show the stress evolution in the overlying strata at the upper left-hand corner of the roof and the lower right-hand corner of the floor after the first excavation step (measurement circles 3 and 6, respectively) and after the second excavation step (measurement circles 31 and 61, respectively). The results in Figure 11(a) show that the internal stress in the surrounding rock at the upper lefthand corner of the roof (measurement circle 3, Figure 8(a)) and the lower right-hand corner of the floor (measurement circle 6, Figure 8(a)) increases during the first excavation step, thus indicating a concentration of stress at the two locations. During the second excavation step (Figure 11(b)), the internal stress in the surrounding rock at measurement circle 31 and circle 61 continues to increase with implementation of the excavation space. However, the increase in pressure is 


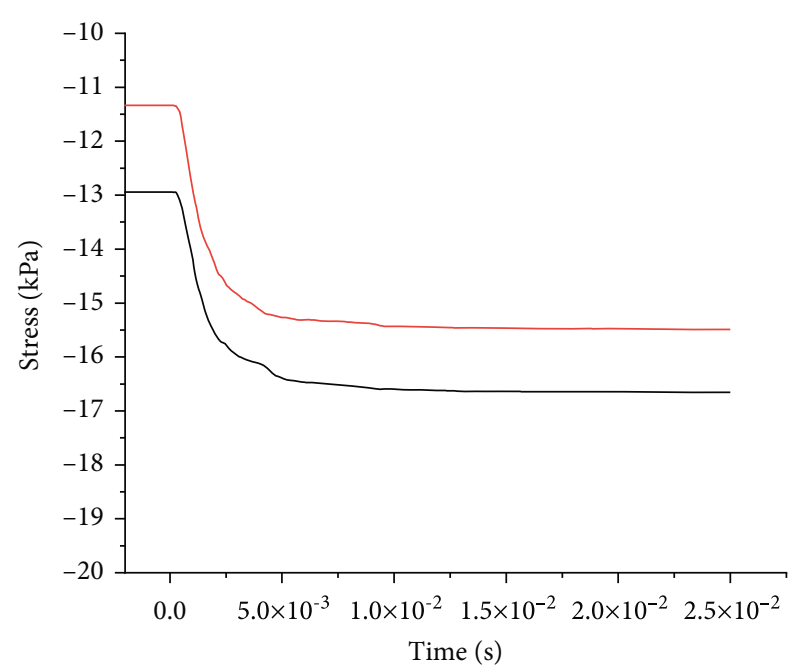

- Measurement circle 3

_ Measurement circle 6

(a) First excavation step

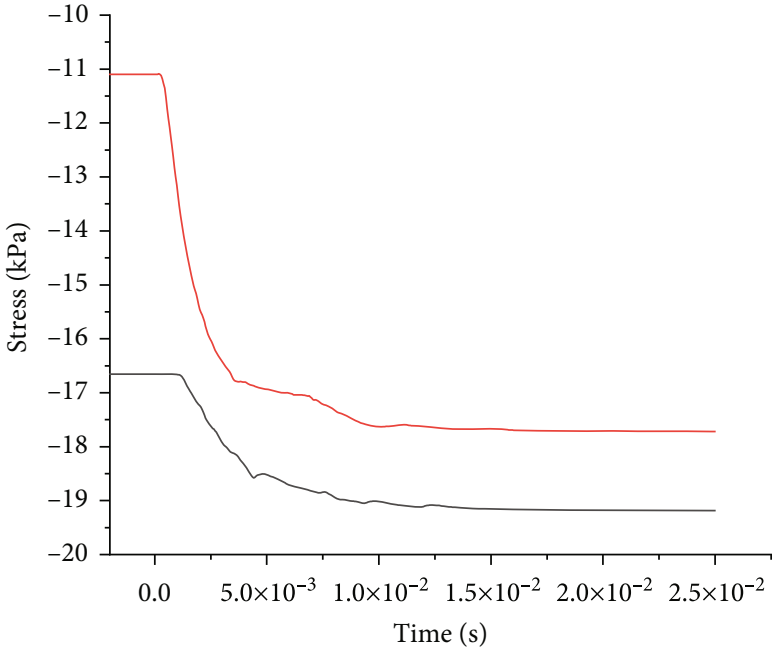

- Measurement circle 31

— Measurement circle 61

(b) Second excavation step

FIGURE 11: Stress evolution in the overlying strata at the upper left-hand corner of the roof and the lower right-hand corner of the floor after the first excavation step (measurement circles 3 and 6, respectively) and after the second excavation step (measurement circles 31 and 61 , respectively).

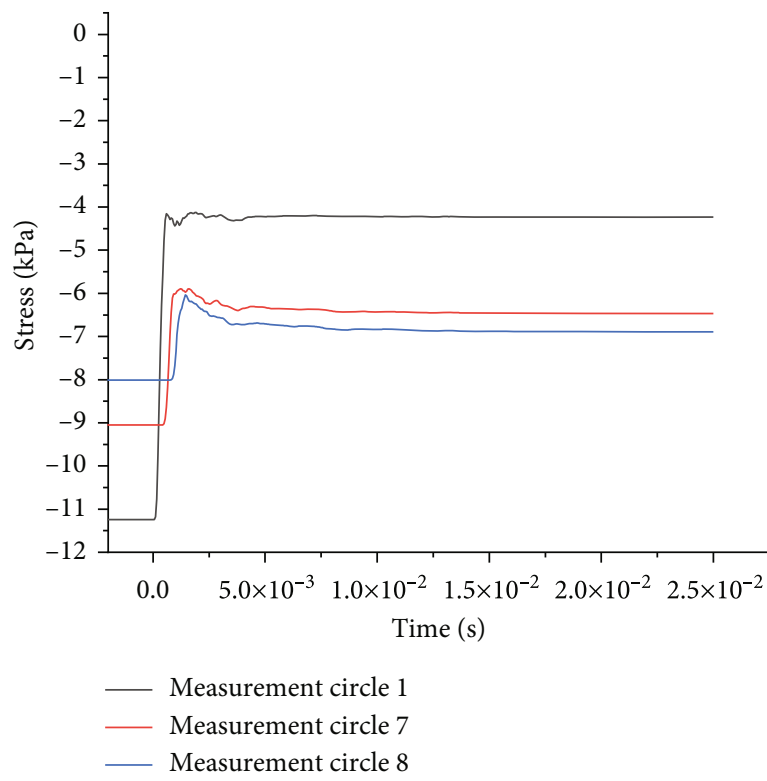

(a) First excavation step

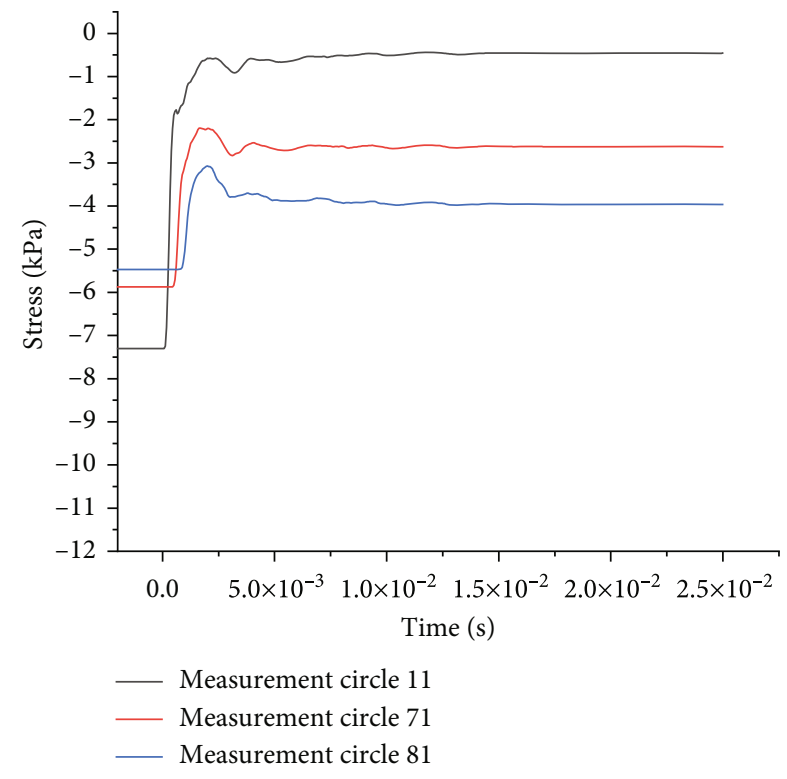

(b) Second excavation step

Figure 12: Stress evolution in the overlying strata at vertical intervals of $0.09 \mathrm{~m}$ on the upper right-hand corner of the roof after the first excavation step (measurement circles 1,7 , and 8 ) and after the second excavation step (measurement circles 11, 71, and 81).

more marked on the lower right, reaching about $6.5 \mathrm{kPa}$. In Figure 9(b), the unloading amplitude of the surrounding rock at the upper right-hand corner of the roof is greater during the second excavation. Hence, due to gravity, the roof has a tendency to move downwards and the stress concentrated in the upper left-hand corner. By contrast, the stress on the surrounding rock on the right-hand side is alleviated by the unloading of the overlying rock in the roof, thus limiting the increase in the internal stress at the lower right-hand corner of the floor.

Figures 12(a) and 12(b) show the stress evolution in the overlying strata at vertical intervals of $0.09 \mathrm{~m}$ on the upper right-hand corner of the roof after the first excavation step (measurement circles 1, 7, and 8) and after the second excavation step (measurement circles 11, 71, and 81). During the first excavation step, the results in Figure 12(a) indicate 


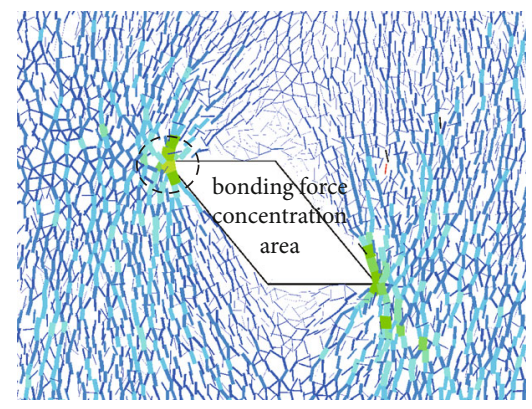

First excavation step

(a) First excavation step

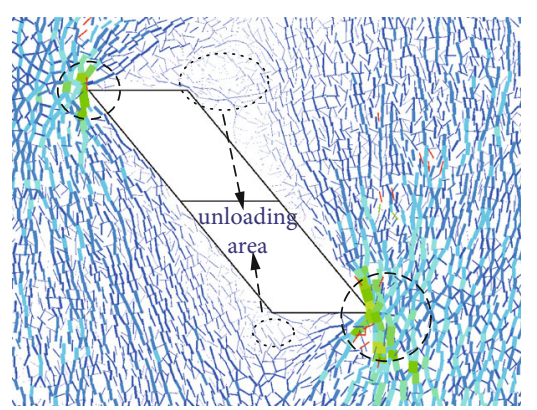

Second excavation step

(b) Second excavation step

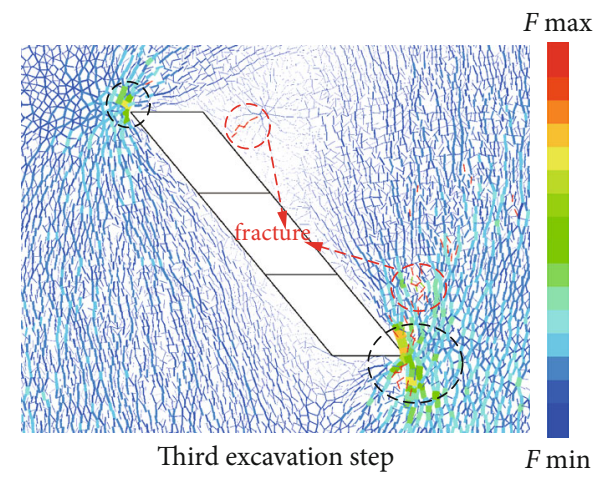

(c) Third excavation step

FIGURE 13: Mesoscale force field distribution and crack propagation during the first, second, and third excavation steps.

that the decrease in the internal stress on the overlying strata varies according to the vertical depth. Specifically, the degree of stress reduction deceases with increasing depth so that the original rock level of stress maintains at a certain depth. After the second excavation step (Figure 12(b)), the pattern of pressure relief with depth is like that at the end of the first excavation step. It is evident that the increase in the minedout area results in a longer fluctuation time for the internal stress in the overlying strata; i.e., the larger the mining space, the longer the overlying rock stress stabilizes.

In brief, the stress evolution curves of overlying strata after various excavation steps (see Figures 8-11) demonstrate that a complicated pattern of internal stress distribution occurs in the adjacent overlying strata during the process of converting from open-pit to underground mining. Thus, both pressure-increasing and pressure-relieving zones exist and are exactly opposite for the roof and the floor. Moreover, the pressure-increasing and pressurereleasing zones in the roof are more severe than those at the floor. In addition, the surrounding rocks on each side form opposite pressure-increasing and pressure-relieving zones during the mining process, with that on the right side being more obvious. Thus, there is an important relationship between the size of the mining space and the pattern of pressure-increasing and pressure-relieving zones. The degree of stress reduction becomes weaken as the distance from the mined-out area increased, and, conversely, the pressure relief becomes more complete closer to the mined-out area, with the stress release being gradually completed towards the deeper parts.
4.4.2. Crack Propagation Behavior of the Surrounding Rock and Overlying Strata after Each Excavation Step. To investigate the mesomechanical characteristics of the surrounding rock and adjacent overlying strata after stepwise excavation, mesoscale distribution of contact forces between particles of binding force $F$ and patterns of crack propagation around the mined-out area are diagrammed in Figures 13-15.

Figures 13(a)-13(c) show the mesoscale force field distribution and crack propagation during the first, second, and third excavation steps, respectively. During step 1, Figure 13(a) reveals the presence of concentrated areas of adhesion at the left-hand corner of the roof and the righthand of the floor, whereas areas of weak adhesion (i.e., pressure-relieving areas) are indicated at the other two corners of the stope. As the excavation space increases during step 2 (see Figure 13(b)), the increase in pressure on the surrounding rocks becomes more marked. At the same time, the pressure-relieving areas become larger and the pressure relief is greater. As mining continues into step 3 (see Figure 13(c)), the internal tensile stress eventually exceeds the bonding tensile strength. The bonds break and microcracks appear in the pressure-relieving area. This result is consistent with the analyses in Figures 8-11 (physical modeling). Note that a few microcracks also appear in the surrounding rock on the bottom right-hand side of the mined-out area due to gravity. Since the mining space is small, there are no large-scale internal cracks, and the surrounding rock and adjacent overlying rocks remain stable after pressure relief.

Figures 14(a)-14(c) show the mesoscale force field distribution and crack propagation during the fourth, fifth, and 


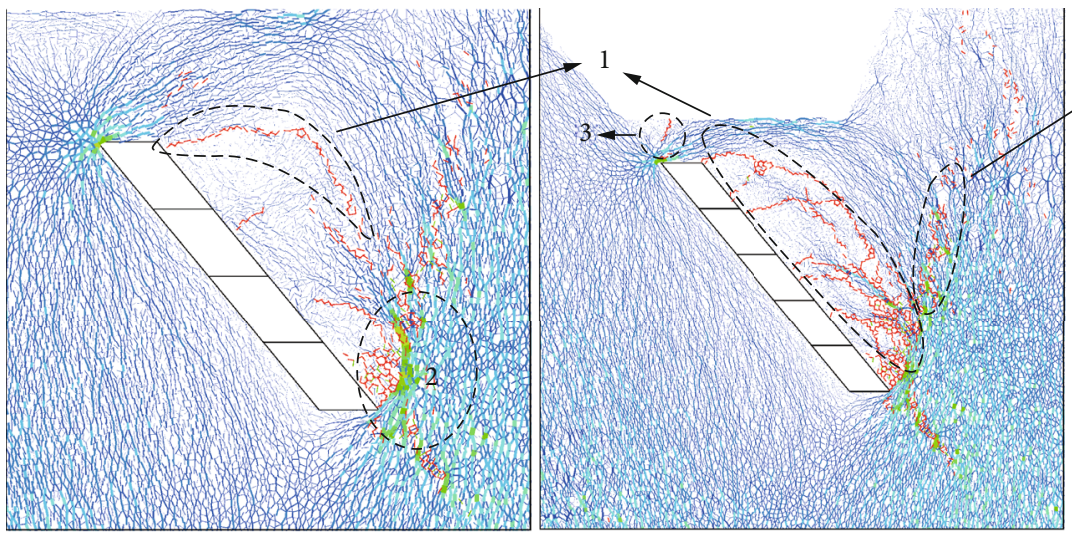

(a) (b)

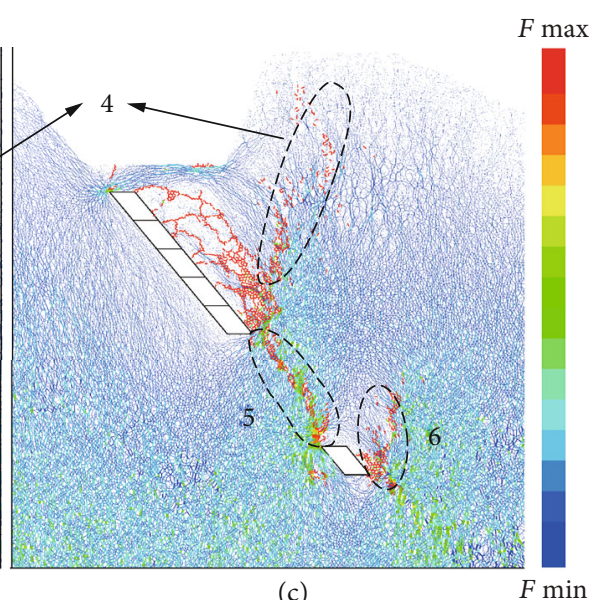

(c)

FIGURE 14: Mesoscale force field distribution and crack propagation during the fourth, fifth, and sixth excavation steps.

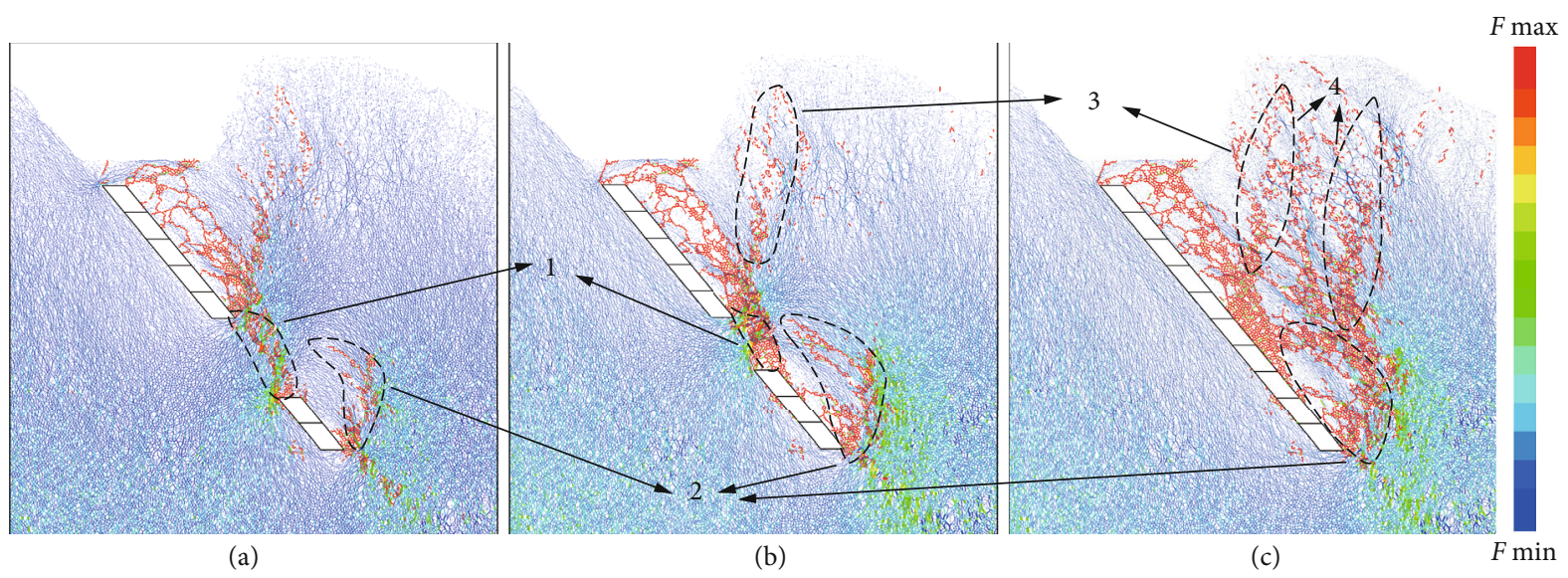

FIGURE 15: Mesoscale force field distribution and crack propagation during the seventh, eighth, and tenth excavation steps.

sixth excavation steps, respectively. With further progress in mining and further increase in the mined-out area during steps 4-6, the cracks expand more noticeably (see Figure 14). During steps 4 and 5, the cracks become arcshaped and tend to penetrate and connect the upper and lower ends of the stope (labelled 1 in Figure 14). As the surrounding rock on the right ruptures and falls, the area of concentrated cohesive force at the bottom of the surrounding rock moves towards right (area 2 in Figure 14). As the roof of the excavation is close to the ground surface, unloading during mining causes the cracks in the roof, which firstly extend to the ground surface (the area labelled 3 in Figure 14(e)). After the lower part of the surrounding rock on the right-hand side falls and collapses, the cracks gradually expand upwards (area 4). When the next mining level is excavated during step 6 (see Figure 14(f)), the cracks between the upper and lower mining levels penetrated (area 5 ). Due to the greater depth of the next mining level, the original rock stress is correspondingly greater and, hence, more cracks form at the bottom of the surrounding rock on the right-hand side. Thus, it leads to faster destruction of the rock mass (area 6).
Figures 15(a)-15(c) show the mesoscale force field distribution and crack propagation during the seventh, eighth, and tenth excavation steps, respectively. During the process of mining the next level, the crack propagation behavior is roughly the same as that under the previous mining level; i.e., the cracks extend in arc shapes and penetrate the upper and lower ends of the stope (area 2 in Figure 15). Due to the increase in mining depth, the crack propagation rate is higher than that of the previous mining level such that the fissures around the two mining levels penetrate each other (area 1, see Figure 15) and subsequently propagate to the surface (areas 3 and 4, see Figure 15). At the end of the final excavation step, the relatively independent mined-out area has disappeared (see Figure 15(c)), causing the number of cracks to increase rapidly and propagate to the surface, thus resulting in overall instability of the mined-out area.

In brief, the crack propagation behavior is characterized by expansion in arc shapes and a tendency to penetrate the upper and lower ends of the stope. Moreover, the size of the excavation space is seen to play a key role in the generation, propagation, and penetration of the cracks. Thus, due to the disturbance of the first mining level and the increase in 
excavation depth, the damage rate of the surrounding rock and overlying rock in the second mining level is greater and more cracks are generated, thus accelerating the instability of the surrounding rock and overlying strata.

\section{Conclusions}

The open-pit end slope, the surrounding rock of the pit bottom, and the underground mine constitute a compound mining system after the transfer from open-pit mining to underground mining. During the period of open-pit mining, the rock around the end of slope and the pit bottom is disturbed and, on this basis, the underground excavation leads to secondary disturbance. With the advancement of the excavation space, the dynamic superposition of this secondary disturbance influences the state of the underground surrounding rock and the overlying strata.

The present study has used similar material models and numerical simulation methods to analyze the settlement curves, stress changes, and crack propagation behavior of the surrounding rock and overlying strata during the process of converting from open-pit to underground mining. The fit of the settlement curve from the model experiment with the numerical calculation illustrated the effectiveness of this simulation method enabling an analysis of the internal stress changes and crack propagation behavior of the surrounding rock and overlying strata during the mining process, and the results can be concluded as follows:

(1) When a gently inclined thin- to medium-thick phosphate deposit was transferred from open-pit to underground mining via a sublevel caving method, the surrounding rock and overlying strata gradually evolved from a stable state through a continuous linear failure state to a final large-scale nonlinear collapse state. The corresponding global subsidence curve was shown to evolve from an irregular ladle shape to a final half-bowl shape

(2) The internal stress distribution of the surrounding rock and adjacent overlying rock in the inclined mined-out area during the process of converting from open-pit to underground mining was shown to be complicated. The degrees of pressure increase and pressure relief on the internal stress of the surrounding rock and the adjacent overlying strata in the mined-out area were shown to have an important relationship with the size of the mining space. Specifically, the degree of stress reduction was weakened with increasing distance, and, conversely, the relief of pressure and the release of stress became gradually more complete towards the deeper part closer to the mined-out area

(3) The cracks were shown to expand in an arc shape and had a tendency to penetrate the upper and lower ends of the stope. The size of the excavation space was found to play a key role in the generation, propagation, and penetration of the cracks. Due to the disturbance of the first mining level and the increase in excavation depth, the rate of damage to the surrounding and overlying rock in the second mining level was greater and more cracks were generated, thus accelerating the instability of the surrounding rock and overlying strata

(4) Many factors were shown to influence the evolution and dynamic characteristics of rock mass deformation and failure after the transition from open-pit to underground mining. It is therefore necessary to study the time-effect and space-time evolution of the mining response characteristics of the rock mass and the effects of various underground mining methods

\section{Data Availability}

Data are available from the authors upon reasonable request.

\section{Conflicts of Interest}

The authors declare that they have no conflict of interest.

\section{Acknowledgments}

The research work described herein was funded by the National Nature Science Foundation of China (NSFC) (Grant No. 41867033), State Key Laboratory of Safety and Health of Metal Mines Open Fund (Grant No. zdsys2019005), China Postdoctoral Science Foundation program (Grant No. 2019M650144). These financial supports are gratefully acknowledged.

\section{References}

[1] R. Q. Huang and S. W. Qi, "Engineering geology: review and prospect of past ten years in China," Journal of Engineering Geology, vol. 25, no. 2, pp. 257-276, 2017.

[2] R. Q. Huang, Y. S. Li, and M. Yan, "The implication and evaluation of toppling failure in engineering geology practice," Journal of Engineering Geology, vol. 25, no. 5, pp. 1165-1181, 2017.

[3] E. Bakhtavar, "Transition from open-pit to underground in the case of Chah-Gaz iron ore combined mining," Journal of Mining Science, vol. 49, no. 6, pp. 955-966, 2013.

[4] C. Li, J. B. Zhu, B. Wang, Y. Z. Jiang, and P. Zeng, "Model tests for mechanical respond of bedding rock during different excavation and anchoring process," Chinese Journal of Underground Space and Engineering, vol. 13, no. 1, pp. 271-278, 2017.

[5] X. S. Li, Y. M. Wang, K. Zhao, and S. Yang, "Research progress on the key problems in transition from open-pit to underground mining for metal mines," Metal Mine, vol. 12, pp. 12-20, 2019.

[6] S. G. Sun, M. F. Cai, and S. J. Wang, "Study of sliding mechanism for slope due to the excavation form open pit into underground mine," Chinese Journal of Rock Mechanics and Engineering, vol. 19, no. 1, pp. 126-129, 2000.

[7] G. Z. Yin, X. S. Li, and Y. J. Li, "Simulation on the deformation and failure response features and stability of a slope from open pit mining to underground mining under the effecting of 
excavation goaf by the floor friction model," Journal of University of Science and Technology Beijing, vol. 34, no. 3, pp. 231238, 2012.

[8] W. D. Song, J. H. Du, X. C. Yang, and D. D. Tannant, "Deformation and failure of a high steep slope due to transformation from deep open pit to underground mining," Journal of University of Science and Technology Beijing, vol. 32, no. 2, pp. 145-151, 2010.

[9] G. Z. Yin, X. S. Li, Z. A. Wei, Y. J. Li, and Q. S. Wang, "Similar simulation study of deformation and failure response features of slope and stope rocks," Chinese Journal of Rock Mechanics and Engineering, vol. 30, Supplement 1, pp. 2913-2923, 2011.

[10] X. S. Li, X. Y. Zhi, D. M. Zhang, and M. L. Wang, "Research on deformation and failure character and the thickness-effect of the overlying strata transition from open pit to underground mining," in National Engineering Geology Annual Conference, Gui Lin City, Guang Xi province, China, 2017.

[11] H. Liu, W. S. Chen, X. T. Feng, and Q. R. Chen, "Numerical modeling of Daye iron open-pit-mine transferring to underground mining by discrete element method," Rock and Soil Mechanics, vol. 25, no. 9, pp. 1413-1417, 2004.

[12] F. Han, F. Xie, and J. A. Wang, "3-D numerical simulation on the stability of rocks in transferred underground mining from open-pit," Journal of University of Science and Technology Beijing, vol. 28, no. 6, pp. 509-514, 2006.

[13] X. Z. Shi, G. H. Huang, S. Zhang, and J. Zhou, "Goaf surrounding rock deformation and failure features using FLAC3D in underground mining shifted from open-pit in complex situation," Journal of Central South University (Science and Technology), vol. 42, no. 6, pp. 1710-1718, 2011.

[14] J. Y. Chen, X. Z. Shi, J. Zhou, and X. Y. Qiu, "Deformation prediction and reliability analysis of underground mining shifted from open-pit based on orthogonal experiment," The Chinese Journal of Nonferrous Metals, vol. 26, no. 11, pp. 2383-2392, 2016.

[15] Y. H. Li, "Study on digital photography-based deformation measurement technique and its application in geo-physical model experiment," Chinese Journal of Rock Mechanics and Engineering, vol. 24, no. 7, p. 184, 2005.

[16] W. D. Song, J. X. Fu, and D. X. Wang, "Study on physical and numerical simulation of failure laws of wall rock due to transformation from open-pit to underground mining," Journal of China Coal Society, vol. 37, no. 2, pp. 186-191, 2012.

[17] Y. F. Wang and F. P. Zhong, "Study on slope instability in transition from open-pit to underground mining by similar experiment and numerical simulation," Journal of China Coal Society, vol. 38, Supplement 1, pp. 64-69, 2013.

[18] D. B. Zhang, Research of Similarity Model Test for Open Pit to Underground Mining with Super High-Steep Slope, China University Of Geosciences, Wuhan, 2013.

[19] Y. M. Zhang, F. S. Ma, J. M. Xu, and H. J. Zhao, "Deformation laws of rock mass due to transform from open-pit to underground mining in high stress area," Rock and Soil Mechanics, vol. 32, Supplement 1, pp. 590-595, 2011.

[20] J. Y. Cao, The Deformation Behavior and Occurrence Mechanism of Pit Surrounding Rock after the Transition from OpenPit Mining to Underground Mining, Shandong University of Science and Technology, Shandong, 2015.

[21] Q. H. Deng, J. Y. Cao, L. P. Zhang, F. S. Ma, and J. M. Xu, "Uplift mechanism of the bottom of open pit after the transition from open-pit mining to underground mining in Long- shou mine," Journal of Mining and Safety Engineering, vol. 32, no. 4, pp. 677-682, 2015.

[22] T. B. Jia, "The dynamic prediction of environment damage induced by the excavation from open-pit into underground mine," Journal of Safety Science and Technology, vol. 11, no. 3, pp. 99-104, 2015.

[23] N. Jiang, C. B. Zhou, S. W. Lu, and Z. Zhang, "Propagation and prediction of blasting vibration on slope in an open pit during underground mining," Tunnelling and Underground Space Technology, vol. 70, no. 1, pp. 409-421, 2017.

[24] G. W. Cheng, C. X. Chen, L. C. Li et al., "Numerical modelling of strata movement at footwall induced by underground mining," International Journal of Rock Mechanics and Mining Sciences, vol. 108, pp. 142-156, 2018.

[25] X. M. Fan, F. Y. Ren, D. Xiao et al., "Improved induced caving mining method for hanging wall ore with deep concave features," Dongbei Daxue Xuebao/Journal of Northeastern University, vol. 39, no. 9, pp. 1321-1326, 2018.

[26] X. M. Fan, F. Y. Ren, D. Xiao, and Y. C. Mao, "Opencast to underground iron ore mining method," Journal of Central South University of Technology Science \& technology of mining and metallurgy, vol. 25, no. 7, pp. 1813-1824, 2018.

[27] F. Y. Ren, B. H. Tan, Y. Fu, and Q. Zhu, "Slope failure caused by hanging-wall ores mining by induced caving method," Journal of Northeastern University (Natural Science), vol. 40, no. 2, pp. 273-277+283, 2019.

[28] B. Regassa, N. Xu, and G. Mei, “An equivalent discontinuous modeling method of jointed rock masses for DEM simulation of mining-induced rock movements," International Journal of Rock Mechanics and Mining Sciences, vol. 108, pp. 1-14, 2018.

[29] K. Xia, C. Chen, Y. Deng et al., "In situ monitoring and analysis of the mining-induced deep ground movement in a metal mine," International Journal of Rock Mechanics and Mining Sciences, vol. 109, pp. 32-51, 2018.

[30] R. Yong, J. Ye, B. Li, and S. G. du, "Determining the maximum sampling interval in rock joint roughness measurements using Fourier series," International Journal of Rock Mechanics and Mining Sciences, vol. 101, pp. 78-88, 2018.

[31] Y. Zhao, T. H. Yang, M. Bohnhoff et al., "Study of the rock mass failure process and mechanisms during the transformation from open-pit to underground mining based on microseismic monitoring," Rock Mechanics and Rock Engineering, vol. 51, no. 5, pp. 1473-1493, 2018.

[32] Q. Y. Zhang, Y. Zhang, K. Duan, C. C. Liu, Y. S. Miao, and $\mathrm{D}$. Wu, "Large-scale geo-mechanical model tests for the stability assessment of deep underground complex under truetriaxial stress," Tunnelling and Underground Space Technology, vol. 83, no. 1, pp. 577-591, 2019.

[33] C. Zhang, P. Zou, Y. Wang, T. Jiang, H. Lin, and P. Cao, “An elasto-visco-plastic model based on stress functions for deformation and damage of water-saturated rocks during the freeze-thaw process," Construction and Building Materials, vol. 250, article 118862, 2020.

[34] C. Zhang, Y. Wang, and T. Jiang, "The propagation mechanism of an oblique straight crack in a rock sample and the effect of osmotic pressure under in-plane biaxial compression," Arabian Journal of Geosciences, vol. 13, no. 15, p. 736, 2020.

[35] R. Cao, R. Yao, J. J. Meng, Q. Lin, H. Lin, and S. Li, "Failure mechanism of non-persistent jointed rock-like specimens under uniaxial loading: laboratory testing," International 
Journal of Rock Mechanics and Mining Sciences, vol. 132, article 104341, 2020.

[36] R. H. Cao, R. Yao, T. Hu, C. Wang, K. Li, and J. Meng, "Failure and mechanical behavior of transversely isotropic rock under compression-shear tests: laboratory testing and numerical simulation," Engineering Fracture Mechanics, vol. 241, article 107389, 2021.

[37] R. H. Cao, C. Wang, R. Yao et al., "Effects of cyclic freeze-thaw treatments on the fracture characteristics of sandstone under different fracture modes: laboratory testing," Theoretical and Applied Fracture Mechanics, vol. 109, article 102738, 2020.

[38] Y. X. Wang, S. B. Shan, C. Zhang, and P. P. Guo, "Seismic response of tunnel lining structure in a thick expansive soil stratum," Tunnelling and Underground Space Technology, vol. 88, pp. 250-259, 2019.

[39] Y. Chen, G. Wen, and J. Hu, "Analysis of deformation characteristics of fully grouted rock bolts under pull-and-shear loading," Rock Mechanics and Rock Engineering, vol. 53, no. 7, pp. 2981-2993, 2020.

[40] Y. Zhao, L. Zhang, J. Liao, W. Wang, Q. Liu, and L. Tang, "Experimental study of fracture toughness and subcritical crack growth of three rocks under different environments," International Journal of Geomechanics, vol. 20, no. 8, article 04020128, 2020.

[41] Y. Zhao, L. Zhang, W. Wang, Q. Liu, L. Tang, and G. Cheng, "Experimental study on shear behavior and a revised shear strength model for infilled rock joints," International Journal of Geomechanics, vol. 20, no. 9, article 04020141, 2020.

[42] Y. Zhao, C. Zhang, Y. Wang, and H. Lin, "Shear-related roughness classification and strength model of natural rock joint based on fuzzy comprehensive evaluation," International Journal of Rock Mechanics and Mining Sciences, vol. 137, article 104550, 2021.

[43] Y. Zhao, C. L. Wang, and J. Bi, "Analysis of fractured rock permeability evolution under unloading conditions by the model of elastoplastic contact between rough surfaces," Rock Mechanics and Rock Engineering, vol. 53, no. 12, pp. 57955808, 2020.

[44] S. J. Xie, H. Lin, Y. Chen, R. Yong, W. Xiong, and S. Du, “A damage constitutive model for shear behavior of joints based on determination of the yield point," International Journal of Rock Mechanics and Mining Sciences, vol. 128, article 104269, 2020.

[45] S. J. Xie, H. Lin, Y. Wang et al., "A statistical damage constitutive model considering whole joint shear deformation," International Journal of Damage Mechanics, vol. 29, no. 6, pp. 988-1008, 2020.

[46] Y. Zheng, C. Chen, F. Meng, H. Zhang, K. Xia, and X. Chen, "Assessing the stability of rock slopes with respect to blockflexure toppling failure using a force-transfer model and genetic algorithm," Rock Mechanics and Rock Engineering, vol. 53, no. 8, pp. 3433-3445, 2020.

[47] R. Jiang, F. Dai, Y. Liu, and A. Li, "Fast marching method for microseismic source location in cavern-containing rockmass: performance analysis and engineering application," Engineering, vol. 4, 2020.

[48] C. Zhang, Y. Wang, H. Ruan, B. Ke, and H. Lin, "The strain characteristics and corresponding model of rock materials under uniaxial cyclic load/unload compression and their deformation and fatigue damage analysis," Archive of Applied Mechanics, 2021.
[49] Y. Zheng, C. Chen, F. Meng, T. Liu, and K. Xia, “Assessing the stability of rock slopes with respect to flexural toppling failure using a limit equilibrium model and genetic algorithm," Computers and Geotechnics, vol. 124, article 103619, 2020.

[50] Y. Zheng, C. Chen, T. Liu, H. Zhang, and C. Sun, "Theoretical and numerical study on the block-flexure toppling failure of rock slopes," Engineering Geology, vol. 263, article 105309, 2019.

[51] Y. Zheng, C. Chen, T. Liu, D. Song, and F. Meng, "Stability analysis of anti-dip bedding rock slopes locally reinforced by rock bolts," Engineering Geology, vol. 251, pp. 228-240, 2019.

[52] Y. Zheng, C. Chen, T. Liu, H. Zhang, K. Xia, and F. Liu, "Study on the mechanisms of flexural toppling failure in anti-inclined rock slopes using numerical and limit equilibrium models," Engineering Geology, vol. 237, pp. 116-128, 2018.

[53] Y. Chen and H. Lin, "Consistency analysis of Hoek-Brown and equivalent Mohr-Coulomb parameters in calculating slope safety factor," Bulletin of Engineering Geology and the Environment, vol. 78, no. 6, pp. 4349-4361, 2019.

[54] H. Lin, H. Yang, Y. Wang, Y. Zhao, and R. Cao, "Determination of the stress field and crack initiation angle of an open flaw tip under uniaxial compression," Theoretical and Applied Fracture Mechanics, vol. 104, article 102358, 2019.

[55] Y. Wang, P. Guo, H. Lin et al., "Numerical analysis of fiberreinforced soils based on the equivalent additional stress concept," International Journal of Geomechanics, vol. 19, no. 11, article 04019122, 2019.

[56] X. Fan, Z. Yang, and K. Li, "Effects of the lining structure on mechanical and fracturing behaviors of four-arc shaped tunnels in a jointed rock mass under uniaxial compression," Theoretical and Applied Fracture Mechanics, vol. 112, p. 102887, 2021.

[57] J. Meng, X. Zhang, J. Huang, H. Tang, H. Mattsson, and J. Laue, "A smoothed finite element method using secondorder cone programming," Computers and Geotechnics, vol. 123, article 103547, 2020.

[58] F. Wang, P. Cao, Y. Wang, R. Hao, J. Meng, and J. Shang, "Combined effects of cyclic load and temperature fluctuation on the mechanical behavior of porous sandstones," Engineering Geology, vol. 266, article 105466, 2020.

[59] K. Li, Y. Cheng, Z. Y. Yin, D. Han, and J. Meng, "Size effects in a transversely isotropic rock under Brazilian tests: laboratory testing," Rock Mechanics and Rock Engineering, vol. 53, no. 6, pp. 2623-2642, 2020.

[60] K. H. Li, Z. Y. Yin, Y. Cheng, P. Cao, and J. Meng, “Threedimensional discrete element simulation of indirect tensile behaviour of a transversely isotropic rock," International Journal for Numerical and Analytical Methods in Geomechanics, vol. 44, no. 13, pp. 1812-1832, 2020.

[61] H. Lin, Y. Zhu, J. Yang, and Z. Wen, "Anchor stress and deformation of the bolted joint under shearing," Advances in Civil Engineering, vol. 2020, Article ID 3696489, 10 pages, 2020.

[62] C. Y. Zhang, C. Pu, R. Cao, T. Jiang, and G. Huang, "The stability and roof-support optimization of roadways passing through unfavorable geological bodies using advanced detection and monitoring methods, among others, in the Sanmenxia Bauxite Mine in China's Henan Province," Bulletin of Engineering Geology and the Environment, vol. 78, no. 7, pp. 5087-5099, 2019.

[63] H. Lin, D. Lei, R. Yong, C. Jiang, and S. du, "Analytical and numerical analysis for frost heaving stress distribution within 
rock joints under freezing and thawing cycles," Environmental Earth Sciences, vol. 79, no. 12, p. 305, 2020.

[64] H. Lin, X. Zhang, R. Cao, and Z. Wen, "Improved nonlinear Burgers shear creep model based on the time-dependent shear strength for rock," Environmental Earth Sciences, vol. 79, no. 6, p. $149,2020$.

[65] Z. M. He, D. Xiang, Y. X. Liu, Q. F. Gao, and H. B. Bian, "Deformation behavior of coarse-grained soil as an embankment filler under cyclic loading," Advances in Civil Engineering, vol. 2020, Article ID 4629105, 13 pages, 2020.

[66] Z. M. He, Z. F. Liu, X. H. Liu, and H. B. Bian, "Improved method for determining active earth pressure considering arching effect and actual slip surface," Journal of Central South University, vol. 27, no. 7, pp. 2032-2042, 2020.

[67] X. Fan, X. Jiang, Y. Liu, H. Lin, K. Li, and Z. He, "Local stress distribution and evolution surrounding flaw and opening within rock block under uniaxial compression," Theoretical and Applied Fracture Mechanics, vol. 112, article 102914, 2021.

[68] H. Ozturk and D. Guner, "Laboratory and distinct element analysis of the deformability behaviour of thin spray-on liners," International Journal of Rock Mechanics and Mining Sciences, vol. 123, article 104118, 2019.

[69] Y. Zhou, D. Zhao, Q. Tang, and M. Wang, "Experimental and numerical investigation of the fatigue behaviour and crack evolution mechanism of granite under ultra-high-frequency loading," Royal Society Open Science, vol. 7, no. 4, 2020.

[70] J. C. Wang, W. J. Wei, J. W. Zhang, B. Mishra, and A. Li, "Numerical investigation on the caving mechanism with different standard deviations of top coal block size in LTCC," International Journal of Mining Science and Technology, vol. 30, no. 5, pp. 34-42, 2020. 